Purdue University

Purdue e-Pubs

$1-1-2008$

\title{
Saturated Flow Boiling Heat Transfer and Pressure Drop in Silicon Microchannel Arrays
}

Poh-Seng Lee

S V. Garimella

Purdue University, sureshg@purdue.edu

Follow this and additional works at: http://docs.lib.purdue.edu/coolingpubs

Lee, Poh-Seng and Garimella, S V., "Saturated Flow Boiling Heat Transfer and Pressure Drop in Silicon Microchannel Arrays" (2008). CTRC Research Publications. Paper 99.

http://dx.doi.org/10.1016/j.ijheatmasstransfer.2007.04.019

This document has been made available through Purdue e-Pubs, a service of the Purdue University Libraries. Please contact epubs@purdue.edu for additional information. 


\title{
Saturated Flow Boiling Heat Transfer and Pressure Drop in Silicon Microchannel Arrays $\$$
}

\author{
Poh-Seng Lee and Suresh V. Garimella ${ }^{\mathbb{T}}$ \\ Cooling Technologies Research Center, School of Mechanical Engineering \\ Purdue University, West Lafayette, Indiana 47907-2088 USA
}

\begin{abstract}
Flow boiling in arrays of parallel microchannels is investigated using a silicon test piece with imbedded discrete heat sources and integrated local temperature sensors. The microchannels considered range in width from $102 \mu \mathrm{m}$ to $997 \mu \mathrm{m}$, with the channel depth being nominally $400 \mu \mathrm{m}$ in each case. Each test piece has a footprint of $1.27 \mathrm{~cm}$ by $1.27 \mathrm{~cm}$ with parallel microchannels diced into one surface. Twenty five microsensors integrated into the microchannel heat sinks allow for accurate local temperature measurements over the entire test piece. The experiments are conducted with deionized water which enters the channels in a purely liquid state. Results are presented in terms of temperatures and pressure drop as a function of imposed heat flux. The experimental results allow a critical assessment of the applicability of existing models and correlations in predicting the heat transfer rates and pressure drops in microchannel arrays, and lead to the development of models for predicting the two-phase pressure drop and saturated boiling heat transfer coefficient.
\end{abstract}

Keywords: Microchannel, electronics cooling, flow boiling, heat sink, local heat transfer coefficient

\footnotetext{
${ }^{\S}$ Submitted for possible publication in International Journal of Heat and Mass Transfer, February 2007

${ }^{\pi}$ Author to whom correspondence should be addressed: 765-494-5621, sureshg@ @urdue.edu
} 


\section{NOMENCLATURE}

$A \quad$ heat sink base area, $\mathrm{cm}^{2}$

$A_{c h} \quad$ channel cross-sectional area, $\mu \mathrm{m}^{2}$

$A_{\text {man }} \quad$ manifold flow cross-sectional area, $\mu \mathrm{m}^{2}$

$A_{t} \quad$ total convection heat transfer area, $\mathrm{m}^{2}$

Bo Boiling number, $B o=\frac{q_{w}{ }^{\prime \prime}}{G h_{f g}}$

$c_{p} \quad$ specific heat, $\mathrm{kJ} / \mathrm{kg}^{\circ} \mathrm{C}$

C Martinelli-Chisholm constant

Co Convection number,

$C o=\left(\frac{1-x}{x}\right)^{0.8}\left(\frac{\rho_{v}}{\rho_{f}}\right)^{0.5}$

$D \quad$ diameter, $\mu \mathrm{m}$

$D_{h} \quad$ hydraulic diameter, $\mu \mathrm{m}$

$f \quad$ friction factor

F convective boiling enhancement factor

$F_{\text {conv }} \quad$ convective boiling enhancement factor

$F_{n b} \quad$ nucleate boiling correction factor

$F_{P F} \quad$ pressure correction factor

$G \quad$ mass flux, $\mathrm{kg} / \mathrm{m}^{2}$

$h \quad$ convective heat transfer coefficient, $\mathrm{W} / \mathrm{m}^{2 \circ} \mathrm{C}$

$H \quad$ channel height, $\mu \mathrm{m}$

$i \quad$ enthalpy, $\mathrm{J} / \mathrm{kg}$

$k$ thermal conductivity, $\mathrm{W} / \mathrm{m}^{\circ} \mathrm{C}$

$K \quad$ loss coefficient

$l \quad$ perimeter, $\mu \mathrm{m}$

L channel length, mm

$L^{+} \quad$ dimensionless hydrodynamic length

nd mass flow rate, $\mathrm{kg} / \mathrm{s}$

$M_{W} \quad$ molecular weight

$N \quad$ number of microchannels

$\mathrm{Nu} \quad$ Nusselt number $\left(N u=h D_{h} / k\right)$ $p_{r} \quad$ reduced pressure

$P \quad$ pressure, $\mathrm{Pa}$

$\operatorname{Pr} \quad$ Prandtl number $\left(\operatorname{Pr}=\mu c_{p} / k\right)$

$q \quad$ effective heat input, $\mathrm{W}$

$q " \quad$ effective heat flux, W/ $/ \mathrm{cm}^{2}$

$q_{s s} \quad$ input power, $\mathrm{W}$

$q_{\text {loss }} \quad$ heat losses, W

$\Delta P \quad$ pressure drop, $\mathrm{Pa}$

$Q \quad$ volumetric flow rate, $\mathrm{m}^{3} / \mathrm{s}$

$q^{\prime \prime} \quad$ heat flux, $\mathrm{W} / \mathrm{m}^{2}$

Re channel Reynolds Number $(\operatorname{Re}=$ $\left.\operatorname{\rho uD}_{\mathrm{h}} / \mu\right)$

$S \quad$ nucleate boiling suppression factor

$t \quad$ substrate thickness, $\mu \mathrm{m}$

T temperature, ${ }^{\circ} \mathrm{C}$

$u \quad$ velocity, $\mathrm{m} / \mathrm{s}$

$V_{d} \quad$ voltage drop across diode, $\mathrm{V}$

$w \quad$ channel width, $\mu \mathrm{m}$

$w_{w} \quad$ channel wall thickness, $\mu \mathrm{m}$

W chip width, mm

We Weber number, $W e=\frac{v_{f} G^{2} D_{h}}{\sigma}$

$x \quad \mathrm{x}$-coordinate, $\mathrm{mm}$

$x_{e} \quad$ thermodynamic equilibrium quality

$X \quad$ Martinelli parameter

$y \quad \mathrm{y}$-coordinate, $\mathrm{mm}$

$z \quad$ z-coordinate (axial distance), $\mathrm{mm}$

$z^{*} \quad$ dimensionless axial distance

\section{Greek}

$\alpha \quad$ channel aspect ratio $(\alpha=\mathrm{H} / \mathrm{w})$

$\alpha_{o} \quad$ void fraction

$\mu \quad$ dynamic viscosity, $\mathrm{Ns} / \mathrm{m}^{2}$ 


$\begin{array}{llll}\rho & \text { density, } \mathrm{kg} / \mathrm{m}^{3} & f d & \text { fully developed } \\ \eta & \text { fin efficiency } & f o & \text { liquid only } \\ v & \text { specific volume, } \mathrm{m}^{3} / \mathrm{kg} & g & \text { vapor } \\ \sigma & \text { surface tension, } \mathrm{N} / \mathrm{m} & h & \text { heater } \\ \tau & \text { shear stress, } \mathrm{N} / \mathrm{m}^{2} & i & \text { manifold inlet } \\ \phi_{f} & \text { two-phase multiplier } & m a n & \text { manifold } \\ \text { Subscripts } & n b & \text { nucleate boiling } \\ 3 & \text { 3-side heating } & o & \text { manifold outlet } \\ 4 & \text { 4-side heating } & r & \text { reduced } \\ \text { ave } & \text { average } & \mathrm{s} & \text { substrate } \\ b & \text { bulk } & s a t & \text { saturated } \\ c h & \text { channel } & s p & \text { single-phase } \\ c i & \text { channel inlet } & s u b & \text { subcooled } \\ c o & \text { channel outlet } & t & \text { thermal } \\ c o n & \text { contraction } & t p & \text { two-phase } \\ d & \text { diode } & t p, a & \text { two-phase accelerational component } \\ d e v & \text { developing } & t p, f & \text { two-phase frictional component } \\ \text { exp } & \text { expansion } & v v & \text { laminar liquid-laminar vapor } \\ \text { expt } & \text { experimental } & w & \text { wall } \\ f & \text { liquid } & z & \text { local } \\ & & \end{array}$

\section{INTRODUCTION}

Flow boiling in microchannels has attracted much attention in recent years due to its potential for extremely high heat transfer rates in compact spaces. Utilizing the latent heat of the coolant, flow boiling can dissipate significantly higher heat fluxes while requiring smaller rates of coolant flow than its singlephase counterpart. Another advantage of the convective boiling process is the greater temperature uniformity across the microchannel heat sinks as the phase-change process takes place at the fluid saturation temperature. In spite of these appealing attributes, the complex nature of convective boiling and two-phase flow in microchannels is still not well understood and this has impeded their wide implementation in practical applications [1-4]. Among the unresolved issues, of particular importance is the quantitative prediction of the saturated flow boiling heat transfer coefficient in microchannels of different sizes over a wide range of mass and heat fluxes. Liu and Garimella [5] conducted a literature survey and pointed out that there was a lack of consensus on the understanding and prediction of boiling 
heat transfer and two-phase flow in microchannels. In addition, although flow-pattern-based models [67] have been proposed to correlate boiling data, these models are typically applicable over a narrow range of experimental conditions. There is thus a clear need for additional systematic studies which carefully address the experimental characterization and modeling of flow boiling in microchannel flows.

The objective of the present work is a comprehensive experimental investigation of saturated flow boiling heat transfer in microchannel heat sinks over a range of channel dimensions. Heat flux, temperature and pressure drop measurements are used to construct boiling curves. Saturated boiling heat transfer and two-phase pressure drop correlations developed for conventional channels are critically appraised for their applicability to the prediction of flow boiling behavior in microchannels. Correlations suitable for the prediction of pressure drop and saturated boiling heat transfer coefficient are proposed.

\section{EXPERIMENTS}

\section{Experimental Setup}

A schematic diagram of the test setup is presented in Figure 1. A three-gallon pressure vessel serves as a reservoir for the deionized water. The fluid is degassed prior to each experimental run. Degassing is achieved by boiling the water in the reservoir vigorously using an imbedded $1000 \mathrm{~W}$ cartridge heater for one and a half hours. The dissolved oxygen (DO) content at the end of this degassing process is $\approx 2.4 \mathrm{ppm}$, as measured by a DO sensor. This amount of residual gas is expected not to affect the boiling behavior [8].

After degassing, the deionized water is driven through the test loop with a gear pump. The fluid first encounters an inline $15 \mu \mathrm{m}$ filter and then passes through a turbine flow meter with a measurement range of $20-200 \mathrm{ml} / \mathrm{min}$. Next, the fluid enters a water-to-water heat exchanger that is hooked up to an external loop. The external loop consists of a $1200 \mathrm{~W}$ inline flow heater, gear pump, temperature controller and reservoir. The temperature controller adjusts the power level of the inline flow heater such that the desired inlet subcooling $\left(10^{\circ} \mathrm{C}\right.$ nominally) is maintained at the testpiece inlet.

The preheated water then enters the test section containing the microchannel heat sink. Constantvoltage power is supplied to the integrated heaters on the backside of the chip to provide the desired heat flux for the flow boiling experiment. Water enters the microchannels as a single-phase liquid and first heats up to its saturation temperature before undergoing phase change. The inlet and outlet fluid pressures and temperatures are measured just upstream and downstream of the microchannels. Holes are drilled into the top cover of the test section for locating the pressure taps and thermocouples. These taps are positioned as close as possible to the microchannels ( $2.54 \mathrm{~mm}$ from both inlet and exit). The temperature distribution on the chip is measured using an integrated $5 \times 5$ diode temperature sensor array. The readings from the pressure transducers and all 25 diode sensors are captured using a high speed PC- 
based data acquisition system with a maximum scan rate of 250,000 samples per second. The thermocouples used for measuring the fluid temperatures and the heater power supply are read using a stand-alone data acquisition unit. All data are then analyzed and stored in a desktop computer.

After exiting the test section, the two-phase fluid enters a water-to-air heat exchanger which cools it before returning to the reservoir. The fluid is then recirculated through the flow loop.

\section{Test Section}

The test section consists of a microchannel test piece, a clear Zelux lid, a quick-connect board and an insulating G10 bottom piece as shown in Figure 2(a). The microchannel test piece is fabricated from a test chip which includes a $5 \times 5$ array of heat sources and temperature-sensing diodes as shown in Figure 2(b). A numbering scheme for the 25 heater/temperature sensor elements is also indicated in the figure. Each of the 25 heater/temperature sensor elements is $2.54 \mathrm{~mm} \times 2.54 \mathrm{~mm}$ in size and incorporates a heating element and integrated diode sensors for on-die temperature monitoring. Resistive heating in the die is accomplished by driving a current through a doped silicon well between a pair of bus bars. At the top and bottom of the die is a pair of pads which connect a serial five-diode temperature sensor network. The thermal test dies are fabricated using a five-inch type-P silicon wafer with orientation 111. The dies are $625 \mu \mathrm{m}$ thick and are diced in arrays of $5 \times 5$, resulting in chips of dimension $12.7 \mathrm{~mm} \times 12.7 \mathrm{~mm}$. The diced chips are mounted on printed circuit boards (PCB) using $63 \mathrm{Sn} / 37 \mathrm{~Pb}$ solder bumps. The microchannels are cut into the top surface (back side) of the chip using a wafer dicing saw with a $100 \mu \mathrm{m}$ wide blade. Depending on the width of the microchannels to be created, single or multiple passes of the saw were made. Table 1 includes the finished dimensions (measured) of the microchannels and the test conditions used.

A transparent Zelux (a type of polycarbonate) cover is used to seal the tops of the microchannels and to provide the plumbing connections. Appropriately designed inlet and outlet manifolds are formed within this cover to minimize the flow mal-distribution across the heat sink. In addition, the manifolds are designed such that any remaining air or vapor entering the test section is trapped in the recessed region of the inlet manifold instead of propagating into the microchannels and affecting the boiling process. Two set-screws are included in the recessed regions in the inlet and outlet manifolds which may be loosened to bleed any trapped air/vapor. Taps are also included for the inlet and outlet pressure transducers and thermocouple probes. A square O-ring seals the test piece while a somewhat flexible, transparent silicone rubber sheet ( $508 \mu \mathrm{m}$ thick) is used as the interface material between the cover and the chip to ensure good sealing of the microchannels. This thin flexible layer accommodates the very slight bowing of the silicon chip at the center due to its mismatch in coefficient of thermal expansion (CTE) with the PCB. 
All electrical connections to the heaters and diode sensors (power input and signal output) are made using a quick-connect board with spring-loaded probes that are pressed against the PCB to establish good contact to the via holes (shown in Figure 2(b)). Such a design eliminates the need to make solder connections with each test piece and significantly reduces the setup time.

\section{Calibration and Heat Loss Characterization}

Before the diode temperature sensors can be used for temperature measurement, their voltagetemperature response is characterized through calibration. The calibration is performed in a convection oven over temperature settings from room temperature to $105^{\circ} \mathrm{C}$, in steps of $10^{\circ} \mathrm{C}$. When the temperature in the oven reaches each desired steady-state value, typically in 45 to 60 minutes, the voltage drop across each diode is recorded. By correlating the voltage drop to temperature, the temperature response of each diode can be established as is illustrated in Figure 3(a). This response is clearly seen to be very linear.

To establish the fraction of the total heat input that is dissipated via the flow boiling process, heat losses via other paths, i.e., natural convection, radiation, and conduction via the $\mathrm{PCB}$, are experimentally determined as follows. The test piece is first completely drained of water. The chip is then heated by applying a constant voltage source to the heaters. A steady state is reached when readings from all diode temperature sensors are within $\pm 0.5^{\circ} \mathrm{C}$ over a two-minute period. The temperature readings from the 25 diodes are then recorded. Tests are repeated for different levels of input power. The average diode temperature is then correlated to the input power and a linear relationship is obtained as shown in Figure 3(b). This relationship, $q_{\text {loss }}=0.09001 T_{d, a v e}-2.00863$, is then used during the flow boiling experiment to account for the heat losses.

\section{Pressure Drop Data Reduction}

As the pressure taps are located upstream and downstream of the microchannels, the measured pressure drop is the sum of pressure drops across the inlet and outlet manifolds, microchannels, and the pressure loss and recovery resulting from the inlet contraction and outlet expansion. Due the close proximity of the pressure taps to the inlet and outlet of the microchannels, the pressure drops in the inlet and outlet manifolds are small compared to the other components and thus can be neglected.

As mentioned earlier, water enters the heat sink in a purely liquid state. The pressure loss associated with the liquid flow contraction at the entrance of the microchannel is given by [9]

$$
\Delta P_{c o n}=\left[1-\left(\frac{N A_{c h}}{A_{\text {man }}}\right)^{2}+K_{c o n}\right] \times \frac{1}{2} G^{2} \nu_{f}
$$

where $K_{c o n}$ is the non-recoverable loss coefficient for laminar flow given by 


$$
K_{\text {con }}=0.0088 \alpha^{2}-0.1785 \alpha+1.6027
$$

The microchannel inlet pressure is then given by

$$
P_{c i}=P_{i}-\Delta P_{c o n}
$$

The pressure recovery due to flow expansion at the exit must be considered separately for single and two-phase flows. For single-phase laminar flow, the exit pressure recovery is given by [9]

$$
\begin{aligned}
& \Delta P_{\text {exp }, s p}=\frac{1}{2} K_{\text {exp }, s p} G^{2} v_{f, o} \\
& K_{\text {exp }, s p}=-2 \times 1.33\left(\frac{N A_{c h}}{A_{\text {man }}}\right)\left[1-\left(\frac{N A_{c h}}{A_{\text {man }}}\right)\right]
\end{aligned}
$$

For two-phase flow, the exit pressure recovery is given by [10]

$$
\Delta P_{e x p, t p}=G^{2}\left[\frac{N A_{c h}}{A_{\text {man }}}\left(\frac{N A_{c h}}{A_{\text {man }}}-1\right)\right] v_{f, o}\left(1-x_{e, o}\right)^{2}\left[1+\frac{5}{X_{v v}}+\frac{1}{X_{v v}^{2}}\right]
$$

In both cases, the microchannel outlet pressure is then given by

$$
P_{c o}=P_{o}+\Delta P_{\text {exp }}
$$

Neglecting the pressure drop in the manifolds, the pressure drop across the microchannels can then be obtained from

$$
\Delta P_{c h}=P_{c i}-P_{c o}
$$

\section{Heat Transfer Data Reduction}

The heat transfer rate to the fluid in the microchannels is obtained by subtracting heat loss from the input power:

$$
q=q_{s s}-q_{\text {loss }}
$$

For the range of conditions considered in this study, over $90 \%$ of the input power is transferred to water once boiling commences in all the experiments.

The associated effective heat flux q" is calculated using the footprint of the heater which is the same as that of the base of the microchannel heat sink, $A=W \times L$. This is also the reported heat flux that the heat sink can dissipate:

$$
q^{\prime \prime}=\frac{q}{A}
$$

A different definition for wall heat flux is used for calculating the heat transfer coefficient, and is defined as

$$
q_{w}^{\prime \prime}=\frac{q}{N(w+\eta 2 H) L}
$$


where $\eta$ is the fin efficiency assuming an adiabatic tip condition

$$
\eta=\frac{\tanh m H}{m H} \text { where } m^{2}=\frac{2 h}{k w_{w}}
$$

It should be noted that the calculation of the fin efficiency requires knowledge of the heat transfer coefficient which is not yet available. An initial guess of the heat transfer coefficient obtained by assuming $100 \%$ fin efficiency is fed into Eq. (11) and an updated value for the heat transfer coefficient is then obtained. This approach is repeated until a prescribed tolerance is met.

Since water enters the microchannels as single-phase liquid $\left(T_{f, i}<T_{s a t, i}\right)$, the length of the channel can be divided into two regions: an upstream single-phase liquid region and a downstream saturated region. It is noted that such a division neglects the presence of a subcooled region, as is accepted practice in the literature $[5,13,18]$; since the inlet fluid temperature is close to its saturated value (subcooling of 4.9 to $9.4^{\circ} \mathrm{C}$ ) the subcooled boiling region extends only over a short distance. The demarcation between the two regions is the location of zero thermodynamic quality where thermodynamic quality is defined as

$$
x_{e}=\frac{i-i_{f}}{i_{g}-i_{f}}
$$

The single-phase liquid region is that over which the thermodynamic quality is negative. The converse applies for the saturated region. The lengths of the two regions can be evaluated from

$$
L_{s p}=\frac{n k_{p}\left(T_{s a t, 0}-T_{f, i}\right)}{q^{\prime \prime} W}
$$

and

$$
L_{s a t}=L-L_{s p}
$$

where $T_{s a t, 0}$ is the saturation temperature at the location of zero thermodynamic quality $\left(x_{e}=0\right)$. Figure 4 schematically illustrates the temperature of the fluid along the length of the microchannel.

To determine $T_{\text {sat }, 0}$, the following approach is used. The saturation temperature of the fluid is assumed to vary linearly with distance, as

$$
T_{\text {sat }}=\left(1-\frac{z}{L}\right) T_{\text {sat }}\left(P_{i}\right)+\frac{z}{L} T_{\text {sat }}\left(P_{o}\right)
$$

where the saturation temperatures at the inlet and outlet are determined based on the pressure measurements. For uniform heat flux conditions, the temperature of the fluid in the single-phase region will also vary linearly according to the energy balance

$$
T_{f}=T_{f, i}+\frac{q^{\prime \prime} W z}{n k_{p}}(\text { Single-phase region })
$$

Solving Eq. (16) and (17) simultaneously allows $T_{s a t, 0}$ and $L_{s p}$ to be determined. Within the saturated region, the local fluid temperature is simply the local saturation temperature 


$$
T_{f}=T_{\text {sat }} \text { (Saturated region) }
$$

The local heat transfer coefficient is determined from

$$
h_{z}=\frac{q_{w}^{\prime \prime}}{T_{w}-T_{f}}
$$

in which $T_{f}$ is the local fluid temperature as defined by Eq. (17) or (18) depending on the region. $T_{w}$ is the local wall temperature which can be obtained by assuming one-dimensional heat conduction through the substrate

$$
T_{w}=T_{d}-\frac{q^{\prime \prime}(t-H)}{k_{s}}
$$

where $T_{d}$ is the temperature of the diode at position 23 , which is the location furthest downstream along the center row (as shown in Figure 2(b)). All the heat transfer results presented in this work are based on this position in the microchannel heat sink.

\section{Measurement Uncertainties}

The uncertainties in individual temperature measurements are $\pm 0.3^{\circ} \mathrm{C}$ for both the T-type thermocouples and the diode temperature sensors employed. The measurement errors for the flow meter and pressure transducers are $1 \%$ and $0.25 \%$ of full scale, respectively. The uncertainty associated with the heat flux measurement is estimated to be $1 \%$ while that associated with the channel dimension measurements varies from $1.5 \%$ for the largest channels to $14.7 \%$ for the smallest channels. A standard error analysis [11] revealed uncertainties in the reported heat transfer coefficients to be in the range of 1.8 to $9.0 \%$.

\section{RESULTS AND DISCUSSION Pressure Drop}

The measured pressure drop between the inlet and exit of the microchannels is shown in Figure 5 as a function of imposed heat flux, and covers the range from purely single-phase flow in the entire microchannel at low heat fluxes to two-phase flow at the higher fluxes. When the incipient heat flux (for the onset of nucleate boiling) is exceeded, the pressure drop increases rapidly with heat flux as the acceleration effect of the generated vapor becomes pronounced.

As discussed in the previous section, the measured pressure drop can be divided into single-phase and saturated two-phase components. The single-phase region can further be sub-divided into a developing and a fully developed region. For the present tests, the Reynolds number based on conditions at the channel inlet is well within the laminar range. The lengths of the developing and fully developed portions of the single-phase region are determined from the following equations 


$$
L_{s p, d e v}=\left\{\begin{array}{l}
L_{s p} \text { if } L_{s p}^{+}<0.05 \\
0.05 \times\left(\operatorname{Re}_{s p} D_{h}\right) \text { if } L_{s p}^{+} \geq 0.05
\end{array}\right.
$$

and

$$
L_{s p, f d}=L_{s p}-L_{s p, d e v}
$$

where $L_{s p}$ is obtained from Eq. (14) and $L_{s p}^{+}=L_{s p} /\left(\operatorname{Re}_{s p} D_{h}\right)$ is the dimensionless hydrodynamic distance. The associated friction factors are evaluated as follows [12]

$$
f_{s p, d e v}=\left\{\begin{array}{l}
\left\{\left[3.2 /\left(0.5 \times L_{s p}^{+}\right)^{0.57}\right]^{2}+\left(f_{f d} \operatorname{Re}_{s p}\right)^{2}\right\} / \operatorname{Re}_{s p} \text { if } L_{s p}^{+}<0.05 \\
\left\{\left[3.2 /(0.5 \times 0.05)^{0.57}\right]^{2}+\left(f_{f d} \operatorname{Re}_{s p}\right)^{2}\right\}^{0.5} / \operatorname{Re}_{s p} \text { if } L_{s p}^{+} \geq 0.05
\end{array}\right.
$$

where

$$
f_{f d}=\frac{96}{\operatorname{Re}_{s p}}\left(1-\frac{1.3553}{\alpha}+\frac{1.9467}{\alpha^{2}}-\frac{1.7012}{\alpha^{3}}+\frac{0.9564}{\alpha^{4}}-\frac{0.2537}{\alpha^{5}}\right)
$$

is the fully developed friction constant for rectangular channel. The pressure drop in the single-phase region can then be obtained from

$$
\Delta P_{s p}=\frac{1}{2} G^{2} v_{f} \frac{\left(f_{s p, d e v} L_{s p, d e v}+f_{s p, f d} L_{s p, f d}\right)}{D_{h}}
$$

The two-phase pressure drop can be expressed as the sum of accelerational and frictional components, as

$$
\Delta P_{t p}=\Delta P_{t p, f}+\Delta P_{t p, a}
$$

A large number of correlations are available for evaluating these two components [13]. The widely used correlation proposed by Lockhart and Martinelli [14] for macroscale channels, and four correlations [1518] developed for mini/microchannels as listed in Table 2 are used for comparison with the experimental measurements obtained.

The Lockhart-Martinelli correlation was based on adiabatic two-phase two-component flow, and can be used to evaluate the frictional pressure drop component using the Martinelli void fraction correlation [13]. While the original Lockhart-Martinelli correlation was developed for turbulent liquidturbulent vapor flow, which is common for macrochannels, the low coolant flow rate and small dimensions of microchannels often result in laminar liquid-laminar vapor flow, as was encountered in the 
present study. The Lockhart-Martinelli correlation was therefore modified with the appropriate Martinelli-Chisholm constant and Martinelli parameter for use in the laminar-laminar regime. The remaining four correlations [15-18] were developed from mini/micro-channel pressure drop data, and employ the Zivi void fraction correlation [19] to evaluate $\Delta P_{t p, a}$.

Predictions of the saturated boiling pressure drop from the five correlations [14-18] are compared in Figure 6 against the experimental data from Case 1-5. It is clear that there is little agreement between the experimental data and the models in the range of heat flux considered, with the correlations either under-predicting [15-17] or over-predicting [14, 18] the data.

Figure 7(a)-(e) further compares $\Delta P_{\text {expt }}$ and $\Delta P_{\text {pred }}$ under all experimental conditions in the present study which allows a critical assessment of the applicability of these five correlations. The mean absolute error (MAE) defined as

$$
M A E=\frac{1}{N} \sum \frac{\left|\Delta P_{c h, \text { expt }}-\Delta P_{c h, p r e d}\right|}{\Delta P_{c h, \text { expt }}}
$$

was computed for each correlation and is provided in Table 2 and in the figure. The comparison with the Lockhart-Martinelli correlation [14] based on laminar liquid and laminar vapor flow yields a MAE of 27.3\%, with a consistent trend of over-prediction. The Mishima and Hibiki correlation [15] is based on a combination of laminar liquid and laminar vapor flow, and also accounts for the channel size effect by incorporating channel hydraulic diameter into the Martinelli-Chisholm constant C, i.e., in Eq. (46). This correlation agrees reasonably well with the present data with a MAE of 22.7\%. Correlations in [16] and [17] utilize a combination of laminar liquid and turbulent vapor flow and generally tend to under-predict the pressure drop data, with MAE values of 34.5 and 55.1\%, respectively. Qu and Mudawar [18] modified the Mishima and Hibiki correlation [15] by incorporating a mass flux term. With a MAE of $16.4 \%$, and with more than $90 \%$ of the data gathered within $\pm 30 \%$ of the prediction, this correlation yields the best agreement among the correlations tested. However, it is observed from Figure 7(e) that this correlation tends to over-predict the pressure drop data. This may be due to the fact that the mass flux term was based on a single microchannel size of $231 \times 713 \mu \mathrm{m}$ in [18].

\section{Proposed Correlation}

In order to improve the predictive capability for microchannels of various sizes, regression analysis is performed on the present data to obtain a more representative mass flux term. An additional channel size correction term is also introduced to more adequately account for the channel size effect. This new correlation is listed as Eq. (66) in Table 2.

Predictions of the saturated boiling pressure drop from the correlation developed in the present work are included in Figure 6. Clearly, the proposed correlation is in very good agreement with the 
experimental pressure drop for Case 1-5. The validity of the proposed model is further examined in Figure 8 by comparing its predictions for all the test cases listed in Table 1. The MAE of $11.4 \%$ from the proposed correlation is significantly better than that of any of the tested correlations and more than $90 \%$ of the data are gathered to within $\pm 30 \%$ of the prediction. Hence, this correlation is suitable for predicting saturated flow boiling pressure drop in microchannels of the dimensions considered in this work.

\section{Boiling Curve}

Figure 9 shows representative boiling curves measured at five streamwise locations along the center row with the diode sensors 3, 8, 13, 18 and 23 (locations shown in Figure 2(b)). The onset of nucleate boiling can be identified in the figure as the point where the wall temperature exhibits a sudden change in slope from its single-phase dependence. In the two-phase region, the heat flux increases rapidly for a modest rise in wall temperature. In addition, the temperature across the chip is more uniform in the two-phase region as can be seen from the converging of the boiling curves. It may be noted that both Figure 9 and Figure 5 provide consistent predictions of the incipience heat flux for the ONB, i.e., qeff" $=$ $35 \mathrm{~W} / \mathrm{cm}^{2}$.

\section{Local Heat Transfer Coefficient}

The presence of local temperature sensors allows the local heat transfer coefficients to be computed. Figure 10 shows the local heat transfer coefficient as a function of wall heat flux at position 23 (central diode in the most downstream location as indicated in Figure 2(b)). For low to medium heat fluxes, the local heat coefficient increases almost linearly with heat flux. At higher heat fluxes, the saturated heat transfer coefficient becomes largely insensitive to heat flux for the range tested.

Predictions from a number of correlations from the literature [17 and 20-23] as listed in Table 3 are compared to the experimental measurements for saturated boiling obtained in the present work. The Chen correlation [20] assumed that both nucleate and two-phase forced convective mechanisms occur to some degree in saturated boiling and that the contributions from the two mechanisms are simply additive. This correlation was developed for turbulent liquid-turbulent vapor flow, which is common for macrochannels. While Kandlikar [24] proposed a correlation for saturated flow boiling heat transfer coefficient based on data for tubes of 3 to $25 \mathrm{~mm}$ diameter with flow in the turbulent regime, this was extended in more recent work [21] to laminar flows in minichannels and microchannels by simply substituting the single-phase laminar fully developed heat transfer coefficient for its turbulent counterpart. Steiner and Taborek [22] developed an asymptotic model utilizing a power-law relationship (with an exponent of 3) for the nucleate and convective dependence as in Eq. (83). According to them, there was 
no evidence for the suppression of nucleate boiling and hence a suppression factor was not needed. Instead, a nucleate boiling correction factor that accounts for the differences between pool and flow boiling was introduced. This correlation was again based on turbulent liquid-turbulent vapor flow boiling in macroscale (vertical) tubes. The two remaining correlations [17, 23] were based on mini/microchannels.

Predictions of the local saturated boiling heat transfer coefficient from these five correlations [17 and 20-23] are compared in Figure 10 against the experimental data in Case 1-2. It is clear that there is little agreement over the range of heat fluxes considered, with four of the tested correlations [20-23] over-predicting the experimental data. Figure 11(a)-(e) further compares $h_{z, \text { expt }}$ and $h_{z, \text { pred }}$ under all operating conditions of the present study, allowing a critical assessment of the applicability of these six correlations. As for the pressure drop comparisons, the mean absolute error (MAE) is defined as

$$
M A E=\frac{1}{N} \sum \frac{\left|h_{z, \text { expt }}-h_{z, p r e d}\right|}{h_{z, \text { expt }}}
$$

The MAE of each of the tested correlations is provided in Table 3 and also indicated in Figure 11(a)-(e). Chen's correlation [20] deviates from the present data with a MAE of 55.0\%. This is because this correlation was developed based on turbulent liquid-turbulent vapor flow in macroscale channels while the low coolant flow rate and small channel size of microchannels encountered in the present study result in laminar liquid-laminar vapor flow. Although the correlation of Kandlikar and Balasubramanian [21] did take into account the laminar flow condition encountered in microchannels, it over-predicts the saturated boiling data with a high MAE of $92.3 \%$. This could be due to the boiling mechanism in microchannels being substantially different from that at the macroscale. The Steiner and Taborek [22] correlation deviates by a MAE of $68.0 \%$ since the original two-phase enhancement factor and the nucleate boiling corrector factor were developed based on flow boiling in macroscale channels. The Yu et al. correlation [17] showed the lowest MAE of $33.5 \%$ (with more than $90 \%$ of the data within $\pm 55 \%$ of the prediction) among the tested correlations. However, the correlation does not correctly capture the experimental trend, and generally under-predicts the data. One possible reason is that this correlation was based on laminar liquid-turbulent vapor flow which is different from the laminar liquid-laminar vapor encountered in the present work. In previous work [25], the authors found that predictions from the empirical correlation of Warrier et al. [23] were in good agreement with the experimental data obtained with microchannels of $400 \mu \mathrm{m}$ width and $398 \mu \mathrm{m}$ depth. However, when tested against experimental results from microchannels over a larger size range, the agreement is found to diminish. This may be attributed to the fact that this correlation was developed based on a curve-fit to experimental results 
obtained from microchannels with a hydraulic diameter of $750 \mu \mathrm{m}$, which appears to have restricted applicability to other microchannel sizes, especially smaller ones as shown in Figure 11(e).

In an effort to improve the predictive capability of correlations, the asymptotic model of Steiner and Taborek [22] was modified to account for the specific features of flow through microchannels. This model was chosen because it is physically sound and does not require the introduction of adjustable parameters that are often arbitrary. In addition, its form allows for further improvement (by substituting individual correlations or data) without necessarily affecting other parts of the model.

\section{Proposed Model}

New correlations for the convective enhancement factor $F_{\text {conv }}$ and the nucleate boiling correction factor $F_{n b}$ are derived as follows:

\section{Convective boiling enhancement factor $F_{\text {conv }}$}

Following the approach of Liu and Garimella [5], it is assumed that the convective component in Eq. (83) can be written in its single-phase form even in two-phase flow. In Chen's original work [20], $h_{s p}$ is the single-phase heat transfer coefficient for turbulent flow. Since the flow in microchannels is typically laminar and thermally developing in nature [26], Lee and Garimella [27] proposed a correlation suitable for predicting laminar and thermally developing heat transfer in rectangular microchannels. For ease of subsequent manipulation, this correlation is re-cast in the following more convenient form

$$
h_{s p}=\left[1.766\left(\operatorname{Re}_{f} \operatorname{Pr}_{f} \frac{D_{h}}{L}\right)^{0.378} \alpha^{0.1224}\right] \frac{k_{f}}{D_{h}}
$$

Following the procedure described in [5], the convective enhancement factor $F$ can then be obtained as

$$
F_{\text {conv }}=\left(\phi_{f}^{2}\right)^{0.2743}\left(\frac{c_{p, t p}}{c_{p, f}}\right)^{0.2743}\left(\frac{k_{t p}}{k_{f}}\right)^{0.7257}
$$

The two-phase multiplier can be related to the Martinelli parameter as

$$
\phi_{f}^{2}=1+\frac{C}{X_{v v}}+\frac{1}{X_{v v}^{2}}
$$

in which the Martinelli-Chisholm constant $\mathrm{C}$ is determined from the previous discussion on pressure drop, i.e., Eq. (66). For laminar flows, the Martinelli parameter is

$$
X_{v v}=\left(\frac{1-x_{e}}{x_{e}}\right)^{0.5}\left(\frac{v_{f}}{v_{g}}\right)^{0.5}\left(\frac{\mu_{f}}{\mu_{g}}\right)^{0.5}
$$

Thus, Eqs. (30) through (32) can be used to determine the convective enhancement factor, $F_{\text {conv }}$, for microchannel flow boiling. The two-phase thermophysical properties in the model can be estimated 
as the arithmetic mean of those of the liquid and vapor phases weighted by the local thermodynamic quality $x_{e}$

$$
\psi_{t p}=x_{e} \psi_{g}+\left(1-x_{e}\right) \psi_{f}
$$

in which $\psi$ is any thermophysical property.

Nucleate boiling correction factor $F_{n b}$

The nucleate boiling correction factor, $F_{n b}$, is obtained from regression analysis once the convective enhancement factor $F_{\text {conv }}$ is known. As the nucleate boiling component is dependent on wall heat flux and is expected to be influenced by the channel size for microchannel flow, $F_{n b}$ is correlated as

$$
F_{n b}=\frac{\left[\left(h_{t p, \text { expt }} \frac{N u_{4}}{N u_{3}}\right)^{3}-\left(F_{\text {conv }} h_{s p}\right)^{3}\right]^{1 / 3}}{h_{n b}} \propto f\left(q_{w}^{\prime \prime}, D_{h}\right)
$$

In Eq. (34), $h_{t p \text { expt }}$ is the measured saturated boiling heat transfer coefficient and $h_{n b}$ is the nucleate boiling heat transfer coefficient which, according to Gorenflo [28] for water, is

$$
h_{n b}=5600 F_{P F}\left(\frac{q_{w}^{\prime \prime}}{20,000}\right)^{0.9-0.3 P_{r}^{0.15}}
$$

where the pressure correction factor $F_{P F}$ for water is

$$
F_{P F}=1.73 p_{r}^{0.27}+\left(6.1+\frac{0.68}{1-p_{r}}\right) p_{r}^{2}
$$

and $p_{r}$ is the reduced pressure.

This approach is applied to the experimental data obtained in the present work to propose the following empirical correlation for the nucleate boiling correction factor, $F_{n b}$, for saturated flow boiling in microchannels

$$
F_{n b}=8.7039-0.6705 \log \left(q_{w}^{\prime \prime}\right)+3908 D_{h}
$$

Predictions of the saturated boiling heat transfer coefficient from this correlation are compared with the experimental data in Figure 10, and show very good agreement for the heat fluxes considered (Case 1-2 shown in the figure). The validity of the proposed model is further demonstrated in Figure 12 for all the test cases listed in Table 1. The MAE of $14.7 \%$ obtained between the experiments and this correlation is significantly better than that for all of the tested correlations and more than $90 \%$ of the data agree to within $\pm 30 \%$ of the prediction. Therefore, this correlation is suitable for predicting the local saturated boiling heat transfer coefficient in microchannels of the dimensions considered in this work.

The proposed model was further validated by comparison with the flow boiling experimental data of Liu and Garimella [5] obtained using copper microchannels of dimensions $275 \times 636 \mu \mathrm{m}$ and $406 \times$ 
$1063 \mu \mathrm{m}$. The predictions from the proposed model were found to agree with the data from [5] with a MAE of $40 \%$. The high thermal conductivity of the copper substrate considered in [5] would lead to some smearing of the local heat transfer data, which may explain the deviation.

\section{CONCLUSIONS}

Flow boiling of water in a microchannel array made of silicon is experimentally investigated. An array of integrated micro-temperature sensors allows local heat transfer coefficients to be determined. The fluid temperatures and pressure drop across the microchannel array are also measured. Two-phase pressure drop and saturated boiling heat transfer correlations from the literature are assessed critically for applicability to microchannels. New correlations suitable for the predicting two-phase pressure drop and local saturated boiling heat transfer coefficient are developed for use in the design two-phase microchannel heat sinks.

Key findings from this work are summarized as follows:

1. A critical review of correlations in the literature suggests that existing correlations in the literature do not match the experimental results obtained for two-phase pressure drop and heat transfer associated with flow boiling in microchannels.

2. A new pressure drop correlation based on the model of Mishima and Hibiki [15] is developed to predict the frictional component, while the Zivi void fraction correlation [19] is employed to evaluate the accelerational component. Comparison with the experimental data shows very good agreement.

3. A new heat transfer correlation, based on the asymptotic model of Steiner and Taborek [22], is developed to predict the local saturated boiling heat transfer coefficient. Comparison with the experimental data again shows satisfactory agreement.

\section{Acknowledgements}

The authors acknowledge the financial support from members of the Cooling Technologies Research Center (www.ecn.purdue.edu/CTRC), a National Science Foundation Industry/University Cooperative Research Center at Purdue University, and from the State of Indiana $21^{\text {st }}$ Century Research and Technology Fund. Assistance with the silicon test pieces from Bruce Myers and Darrel Peugh of Delphi Electronics and Safety, Kokomo, Indiana, is gratefully acknowledged.

\section{REFERENCES}

1. C.B. Sobhan, S.V, Garimella, A comparative analysis of studies on heat transfer and fluid flow in microchannels, Microscale Thermophys. Eng. 5 (2001) 293-311. 
2. S.G. Kandlikar, Fundamental issues related to flow boiling in minichannels and microchannels, Exp. Thermal and Fluid Science 26 (2002) 389-407.

3. A.E. Bergles, V.J.H. Lienhard, G.E. Kendall, P. Griffith, Boiling and evaporation in small diameter channels, Heat Transfer Engineering 24 (2003) 18-40.

4. J.R. Thome, Boiling in microchannels: a review of experiment and theory, Int. J. Heat Fluid Flow 25 (2004) 128-139.

5. D. Liu, S.V. Garimella, Flow boiling heat transfer in microchannels, J. Heat Transfer (In Press, 2007).

6. W. Qu, I. Mudawar, Flow Boiling Heat Transfer in Two-Phase Microchannel Heat Sinks - II. Annular Two-Phase Flow Model, Int. J. Heat Mass Transfer 46 (2003) 2773-2784.

7. J.R. Thome, V. Dupont, A.M. Jacobi, Heat Transfer Model for Evaporation in Microchannels. Part I: Presentation of the Model, Int. J. Heat Mass Transfer 47 (2004) 3375-3385.

8. M.E. Steinke, S.G. Kandlikar, Control and effect of dissolved air in water during flow boiling in microchannels, Int. J. Heat Mass Transfer 47 (2004) 1925-1935.

9. R.D. Blevins, Applied Fluid Dynamics Handbook, Krieger Pub. Co., 1992, 77-78.

10. D. Chisholm, L.A. Sutherland, Prediction of pressure gradients in pipeline systems during two-phase flow, Symposium in Two-phase Flow Systems, Univ. of Leeds (1969).

11. J.R. Taylor, An Introduction to Error Analysis, University Science Books, 1997.

12. R.K. Shah, A.L. London, Laminar flow forced convection in ducts, Advances in Heat Transfer Supplement 1 (1978), Academic Press.

13. J.G. Collier, J.R. Thome, Convective Boiling and Condensation, Third ed., Oxford University Press, Oxford, 1994.

14. R.W. Lockhart, R.C. Martinelli, Proposed correlation of data for isothermal two-phase, twocomponent flow in pipes, Chem. Eng. Prog. 45 (1949) 39-48.

15. K. Mishima, T. Hibiki, Some characteristics of air-water two-phase flow in small diameter vertical tubes, Int. J. Multiphase Flow 22 (1996) 703-712.

16. H.J. Lee, S.Y. Lee, Heat transfer correlation for boiling flows in small rectangular horizontal channels with low aspect ratios, Int. J. Multiphase Flow 27 (2001) 2043-2062.

17. W. Yu, D.M. France, M.W. Wambsganss, J.R. Hull, Two-phase pressure drop, boiling heat transfer, and critical heat flux to water in a small-diameter horizontal tube, Int. J. Multiphase Flow 28 (2002) 927-941.

18. W. Qu, I. Mudawar, Measurement and prediction of pressure drop in two-phase micro-channel heat sinks, Int. J. Heat Mass Transfer 46 (2003) 2737-2753. 
19. S.M. Zivi, Estimation of steady-state steam void-fraction by means of the principle of minimum entropy production, J. Heat Transfer 86 (1964) 247-252.

20. J.C. Chen, Correlation for boiling heat transfer to saturated fluids in convective flow, I\&EC Process Design and Development 5 (1966) 322-329.

21. S.G. Kandlikar, P. Balasubramanian, An extension of the flow boiling correlation to transition, laminar and deep laminar flows in minichannels and microchannels, Heat Transfer Engineering, 25 (2004) 86-93.

22. D. Steiner, J. Taborek, Flow boiling heat transfer in vertical tubes correlated by an asymptotic model, Heat Transfer Eng. 13 (1992) 43-68.

23. G.R. Warrier, V.K. Dhir, L.A. Momoda, Heat transfer and pressure drop in narrow rectangular channel, Exp. Therm. Fluid Sci. 26 (2002) 53-64.

24. S.G. Kandlikar, A general correlation for saturated two-phase flow boiling heat transfer inside horizontal and vertical tubes, J. Heat Transfer 112 (1990) 219-228.

25. P.-S. Lee, S.V. Garimella, Flow boiling in a silicon microchannel array, Proceedings of ASME IMECE, Chicago, IL 2005.

26. P.-S. Lee, S.V. Garimella, D. Liu, Experimental investigation of heat transfer in microchannels, Int. J. Heat Mass Transfer 48 (2005) 1688-1704.

27. P.-S. Lee, S.V. Garimella, Thermally developing flow and heat transfer in rectangular microchannels of different aspect ratios, Int. J. Heat Mass Transfer 49 (2006) 3060-3067.

28. D. Gorenflo, Pool Boiling, VDI-Heat Atlas, VDI-Verlag, Dusseldorf, Germany, 1993. 


\section{LIST OF TABLES}

Table 1. Test matrix used for flow boiling pressure drop and heat transfer study.

Table 2. Two-phase pressure drop correlations.

Table 3. Saturated boiling correlations.

\section{LIST OF FIGURE CAPTIONS}

Figure 1. Schematic diagram of experimental test set-up.

Figure 2. (a) Microchannel test section, and (b) $5 \times 5$ array of heating elements and integrated diode temperature sensors.

Figure 3. (a) Typical calibration curve of a silicon diode temperature sensor, and (b) heat loss characterization.

Figure 4. Schematic representation of the fluid temperature along the microchannel.

Figure 5. Pressure drop over the length of the microchannels for Case 3-3 ( $\mathrm{w}=400 \mu \mathrm{m}, \mathrm{H}=398$ $\mu \mathrm{m}, \mathrm{T}_{\mathrm{f}, \mathrm{i}}=91.3^{\circ} \mathrm{C}$ and $\mathrm{G}=432 \mathrm{~kg} / \mathrm{m}^{2} \mathrm{~s}$ ).

Figure 6. Assessment of correlations in the literature based on comparison with pressure drop over the length of the microchannels for Case $1-5\left(\mathrm{w}=102 \mu \mathrm{m}, \mathrm{H}=367 \mu \mathrm{m}, \mathrm{T}_{\mathrm{f}, \mathrm{i}}=91.1^{\circ} \mathrm{C}\right.$ and $\mathrm{G}$ $=738 \mathrm{~kg} / \mathrm{m}^{2} \mathrm{~s}$ ).

Figure 7. Comparison of two-phase pressure drop data with predictions by correlations of (a) Lockhart and Martinelli [14], (b) Mishimi and Hibiki [15], (c) Lee and Lee [16], (d) Yu et al. [17], and (e) Qu and Mudawar [18] for all test conditions.

Figure 8. Comparison of two-phase pressure drop experimental data with predictions by proposed prediction for all test conditions.

Figure 9. Typical boiling curves measured at five streamwise locations along the center of the chip for Case 3-3 ( $=400 \mu \mathrm{m}, \mathrm{H}=398 \mu \mathrm{m}, \mathrm{T}_{\mathrm{f}, \mathrm{i}}=91.3^{\circ} \mathrm{C}$ and $\left.\mathrm{G}=432 \mathrm{~kg} / \mathrm{m}^{2} \mathrm{~s}\right)$.

Figure 10. Assessment of correlations in the literature based on comparison with experimental data from the present work at position 23 for Case $1-2\left(\mathrm{w}=102 \mu \mathrm{m}, \mathrm{H}=367 \mu \mathrm{m}, \mathrm{T}_{\mathrm{f}, \mathrm{i}}=93.6^{\circ} \mathrm{C}\right.$ and $\mathrm{G}=368 \mathrm{~kg} / \mathrm{m}^{2} \mathrm{~s}$ ).

Figure 11. Comparison of saturated boiling heat transfer data with predictions from the correlations of (a) Chen [20], (b) Kandlikar and Balasubramanian [21], (c) Steiner and Taborek [22], (d) Yu et al. [17], and (e) Warrier et al. [23] for all test conditions.

Figure 12. Comparison of saturated boiling heat transfer data with predictions by proposed correlation for all test conditions. 
Table 1. Test matrix used for flow boiling pressure drop and heat transfer study.

\begin{tabular}{|c|c|c|c|c|c|c|c|c|}
\hline Case & $\begin{array}{c}w \\
(\mu \mathrm{m})\end{array}$ & $\underset{(\mu \mathrm{m})}{\boldsymbol{H}}$ & $\begin{array}{c}w_{w} \\
(\mu \mathrm{m})\end{array}$ & $N$ & $\begin{array}{c}Q \\
(\mathrm{ml} / \mathrm{min})\end{array}$ & $\begin{array}{c}T_{f, i} \\
\left({ }^{\circ} \mathrm{C}\right)\end{array}$ & $\begin{array}{c}q_{s s}{ }^{\prime \prime} \\
\left(\mathrm{W} / \mathrm{cm}^{2}\right)\end{array}$ & $\begin{array}{c}x_{e} \\
(\%)\end{array}$ \\
\hline $\begin{array}{l}1-1 \\
1-2 \\
1-3 \\
1-4 \\
1-5 \\
1-6\end{array}$ & 102 & 367 & 98 & 60 & $\begin{array}{c}46 \\
50 \\
60 \\
76 \\
101 \\
126\end{array}$ & $\begin{array}{l}95.1 \\
93.6 \\
92.7 \\
91.9 \\
91.1 \\
90.6\end{array}$ & $\begin{array}{l}10-230 \\
10-240 \\
10-231 \\
10-251 \\
10-301 \\
10-310\end{array}$ & $\begin{aligned} &-1.19 \sim 19.87 \\
&-1.14 \sim 17.51 \\
&-1.35 \sim 14.37 \\
&-1.48 \sim 11.63 \\
&-1.61 \sim 9.73 \\
&-1.72 \sim 7.18\end{aligned}$ \\
\hline $\begin{array}{l}2-1 \\
2-2 \\
2-3 \\
2-4 \\
2-5\end{array}$ & 242 & 365 & 108 & 35 & $\begin{array}{c}52 \\
63 \\
84 \\
104 \\
126\end{array}$ & $\begin{array}{l}94.1 \\
93.2 \\
92.3 \\
92.0 \\
91.4\end{array}$ & $\begin{array}{l}10-151 \\
10-161 \\
10-181 \\
10-221 \\
10-231\end{array}$ & $\begin{aligned}-1.40 & \sim 11.30 \\
-1.57 & \sim 9.71 \\
-1.60 & \sim 7.73 \\
-1.65 & \sim 7.27 \\
-1.71 & \sim 5.83\end{aligned}$ \\
\hline $\begin{array}{l}3-1 \\
3-2 \\
3-3 \\
3-4\end{array}$ & 400 & 398 & 100 & 24 & $\begin{array}{c}50 \\
75 \\
101 \\
125\end{array}$ & $\begin{array}{l}94.5 \\
92.2 \\
91.3 \\
90.9\end{array}$ & $\begin{array}{l}10-190 \\
10-220 \\
10-260 \\
10-280\end{array}$ & $\begin{array}{r}-1.47 \sim 14.75 \\
-1.64 \sim 10.61 \\
-1.64 \sim 8.82 \\
-1.72 \sim 7.07 \\
\end{array}$ \\
\hline $\begin{array}{l}4-1 \\
4-2 \\
4-3 \\
4-4\end{array}$ & 997 & 369 & 243 & 10 & $\begin{array}{c}51 \\
76 \\
101 \\
126\end{array}$ & $\begin{array}{l}92.2 \\
90.8 \\
90.7 \\
90.6\end{array}$ & $\begin{array}{l}10-234 \\
10-289 \\
10-320 \\
10-340\end{array}$ & $\begin{aligned}-1.40 & \sim 17.94 \\
-1.27 \sim 13.79 & \sim 10.94 \\
-1.55 & \sim 10.95 \\
-1.65 & \sim 8.58\end{aligned}$ \\
\hline
\end{tabular}


Table 2. Two-phase pressure drop correlations.

\begin{tabular}{|c|c|c|c|c|c|}
\hline Reference & Frictional component, $\Delta P_{t p, f}$ & & Accelerational component, $\Delta \boldsymbol{P}_{t p, f}$ & & $\begin{array}{l}\text { MAE } \\
\text { (\%) }\end{array}$ \\
\hline $\begin{array}{l}\text { Lockhart and } \\
\text { Martinelli [14] }\end{array}$ & $\begin{array}{l}\Delta P_{t p, f}=L_{s a t} / x_{e, o} \int_{0}^{x_{w}} 2 \phi_{f}^{2} f_{f} G^{2}\left(1-x_{e}\right)^{2} v_{f} / D_{h} \mathrm{~d} x_{e} \\
f_{f}=96 / \operatorname{Re}_{f}\left(1-1.3553 \alpha^{-1}+1.9467 \alpha^{-2}-1.7012 \alpha^{-3}+0.9564 \alpha^{-4}-0.2537 \alpha^{-5}\right) \\
\operatorname{Re}_{f}=G\left(1-x_{e}\right) D_{h} / \mu_{f} \\
\phi_{f}^{2}=1+C / X_{w}+1 / X_{w}^{2}, C=5 \\
X_{w}=\left(\mu_{f} / \mu_{g}\right)^{0.5}\left[\left(1-x_{e}\right) / x_{e}\right]^{0.5}\left(v_{f} / v_{g}\right)^{0.5}\end{array}$ & $\begin{array}{l}(38) \\
(40) \\
(41) \\
(42)\end{array}$ & $\begin{array}{l}\Delta P_{p p, a}=G^{2} v_{f}\left[x_{e, o}^{2} / \alpha_{o}\left(v_{s} / v_{f}\right)+\left(1-x_{e, o}\right)^{2} /\left(1-\alpha_{o}\right)-1\right] \\
\alpha_{o}=1-1 / \sqrt{1+20 / X_{w, o}+1 / X_{w, o}^{2}}\end{array}$ & $\begin{array}{l}(43) \\
(44)\end{array}$ & 27.3 \\
\hline $\begin{array}{l}\text { Mishimi and } \\
\text { Hibiki [15] }\end{array}$ & $\begin{array}{l}\Delta P_{t p, f}=L_{s a t} / x_{e, o} \int_{0}^{x_{w}} 2 \phi_{f}^{2} f_{f} G^{2}\left(1-x_{e}\right)^{2} v_{f} / D_{h} \mathrm{~d} x_{e} \\
\phi_{f}^{2}=1+C / X_{w}+1 / X_{w w}^{2}, C=21\left(1-e^{-310 D_{s}}\right)\end{array}$ & $\begin{array}{l}(45) \\
(46)\end{array}$ & $\begin{array}{l}\Delta P_{t p, a}=G^{2} v_{f}\left[x_{e, o}^{2} / \alpha_{o}\left(v_{g} / v_{f}\right)+\left(1-x_{e, o}\right)^{2} /\left(1-\alpha_{o}\right)-1\right] \\
\alpha_{o}=1 /\left[1+\left(1-x_{e, o}\right) / x_{e, o}\left(v_{f} / v_{g}\right)^{2 / 3}\right]\end{array}$ & $\begin{array}{l}(47) \\
(48)\end{array}$ & 22.7 \\
\hline $\begin{array}{l}\text { Lee and Lee } \\
{[16]}\end{array}$ & $\begin{array}{l}\Delta P_{t, f}=L_{s a t} / x_{e, o} \int_{0}^{x_{w}} 2 \phi_{f}^{2} f_{f} G^{2}\left(1-x_{e}\right)^{2} v_{f} / D_{h} \mathrm{~d} x_{e} \\
\phi_{f}^{2}=1+C / X_{v t}+1 / X_{v t}^{2}, C=6.185 \times 10^{-2} \operatorname{Re}_{f o}^{0.726} \\
\operatorname{Re}_{f o}=G D_{h} / \mu_{f} \\
f_{f}=96 / \operatorname{Re}_{f}\left(1-1.3553 \alpha^{-1}+1.9467 \alpha^{-2}-1.7012 \alpha^{-3}+0.9564 \alpha^{-4}-0.2537 \alpha^{-5}\right)\end{array}$ & $\begin{array}{l}(49) \\
(50) \\
(51) \\
(52)\end{array}$ & $\begin{array}{l}\Delta P_{t p, a}=G^{2} v_{f}\left[x_{e, o}^{2} / \alpha_{o}\left(v_{g} / v_{f}\right)+\left(1-x_{e, o}\right)^{2} /\left(1-\alpha_{o}\right)-1\right] \\
\alpha_{o}=1 /\left[1+\left(1-x_{e, o}\right) / x_{e, o}\left(v_{f} / v_{g}\right)^{2 / 3}\right]\end{array}$ & $\begin{array}{l}(53) \\
(54)\end{array}$ & 34.5 \\
\hline Yu et al. [17] & $\begin{array}{l}\Delta P_{t p, f}=L_{s a t} / x_{e, o} \int_{0}^{x_{s}} 2 \phi_{f}^{2} f_{f} G^{2}\left(1-x_{e}\right)^{2} v_{f} / D_{h} \mathrm{~d} x_{e} \\
\phi_{f}^{2}=1 / X_{v t}^{1.9} \\
X_{v t}=\left(f_{f} \operatorname{Re}_{g}^{0.2} / 0.046\right)^{0.5}\left[\left(1-x_{e}\right) / x_{e}\right]\left(v_{f} / v_{g}\right)^{0.5} \\
\operatorname{Re}_{s}=G x_{e} D_{h} / \mu_{g}\end{array}$ & $\begin{array}{l}(55) \\
(56) \\
(57) \\
(58)\end{array}$ & $\begin{array}{l}\Delta P_{t, a}=G^{2} v_{f}\left[x_{e, o}^{2} / \alpha_{o}\left(v_{s} / v_{f}\right)+\left(1-x_{e, o}\right)^{2} /\left(1-\alpha_{o}\right)-1\right] \\
\alpha_{o}=1 /\left[1+\left(1-x_{e, o}\right) / x_{e, o}\left(v_{f} / v_{g}\right)^{2 / 3}\right]\end{array}$ & $\begin{array}{l}(59) \\
(60)\end{array}$ & 55.1 \\
\hline $\begin{array}{l}\text { Qu and } \\
\text { Mudawar [18] }\end{array}$ & $\begin{array}{l}\Delta P_{t p, f}=L_{s a t} / x_{e, o} \int_{0}^{x_{w}} 2 \phi_{f}^{2} f_{f} G^{2}\left(1-x_{e}\right)^{2} v_{f} / D_{h} \mathrm{~d} x_{e} \\
\phi_{f}^{2}=1+C / X_{w}+1 / X_{w}^{2}, C=21\left(1-e^{-311 D_{i}}\right)(0.00418 G+0.0613)\end{array}$ & $\begin{array}{l}(61) \\
(62)\end{array}$ & $\begin{array}{l}\Delta P_{p, a}=G^{2} v_{f}\left[x_{e, o}^{2} / \alpha_{o}\left(v_{g} / v_{f}\right)+\left(1-x_{e, o}\right)^{2} /\left(1-\alpha_{o}\right)-1\right] \\
\alpha_{o}=1 /\left[1+\left(1-x_{e, o}\right) / x_{e, o}\left(v_{f} / v_{g}\right)^{2 / 3}\right]\end{array}$ & $\begin{array}{l}(63) \\
(64)\end{array}$ & 16.4 \\
\hline Present work & $\begin{array}{l}\Delta P_{t p, f}=L_{s a t} / x_{e, o} \int_{0}^{x_{w o}} 2 \phi_{f}^{2} f_{f} G^{2}\left(1-x_{e}\right)^{2} v_{f} / D_{h} \mathrm{~d} x_{e} \\
\phi_{f}^{2}=1+C / X_{w}+1 / X_{w}^{2}, C=2566 G^{0.5466} D_{h}^{0.8819}\left(1-e^{-319 D_{s}}\right)\end{array}$ & $\begin{array}{l}(65) \\
(66)\end{array}$ & $\begin{array}{l}\Delta P_{t p, a}=G^{2} v_{f}\left[x_{e, o}^{2} / \alpha_{o}\left(v_{g} / v_{f}\right)+\left(1-x_{e, o}\right)^{2} /\left(1-\alpha_{o}\right)-1\right] \\
\alpha_{o}=1 /\left[1+\left(1-x_{e, o}\right) / x_{e, o}\left(v_{f} / v_{g}\right)^{2 / 3}\right]\end{array}$ & $\begin{array}{l}(67) \\
(68)\end{array}$ & 11.4 \\
\hline
\end{tabular}


Table 3. Saturated boiling correlations.

\begin{tabular}{|c|c|c|c|}
\hline Reference & Correlation & & MAE (\%) \\
\hline Chen [20] & $\begin{array}{l}h_{s a t}=N u_{3} / N u_{4} \times\left(F h_{s p}+S h_{n b}\right) \\
F=\left(1+X_{t t}^{-0.5}\right)^{1.78} \\
S=0.9622-0.5822 \tan ^{-1}\left(\operatorname{Re}_{f} F^{1.25} / 6.18 \times 10^{4}\right) \\
h_{s p}=0.023 \operatorname{Re}_{f}^{0.8} \operatorname{Pr}_{f}^{1 / 3}\left(k_{f} / D_{h}\right) \\
h_{n b}=0.0122\left(\frac{k_{f}^{0.79} c_{p, f}^{0.45} \rho_{f}^{0.49}}{\sigma^{0.5} \mu_{f}^{0.29} h_{f g}^{0.24} \rho_{v}^{0.24}}\right)\left(T_{w}-T_{s}\right)^{0.24}\left[P_{s a t}\left(T_{w}\right)-P_{f}\right]^{0.75}\end{array}$ & $\begin{array}{l}(69) \\
(70) \\
(71) \\
(72) \\
(73)\end{array}$ & 55.0 \\
\hline $\begin{array}{l}\text { Kandlikar and } \\
\text { Balasubramanian } \\
\text { [21] }\end{array}$ & $\begin{array}{l}h_{s a t}=N u_{3} / N u_{4} \times \max \left(h_{s a t, N B D}, h_{s a t, C B D}\right) \\
h_{s a t, N B D}=\left(0.6683 C o^{-0.2}+1058.0 B o^{0.7} F_{f l}\right)\left(1-x_{e}\right)^{0.8} h_{s p, f d} \\
h_{s a t, C B D}=\left(1.136 C o^{-0.9}+667.2 B o^{0.7} F_{f l}\right)\left(1-x_{e}\right)^{0.8} h_{s p, f d} \\
\text { where } F_{f l}=1.00 \text { for water }\end{array}$ & (74) & 92.3 \\
\hline Yu et al. [17] & $\begin{array}{l}h_{s a t}=N u_{3} / N u_{4} \times\left(F h_{s p}+S h_{n b}\right) \\
F=\left(1+X_{t t}^{-0.5}\right)^{1.78} \\
S=0.9622-0.5822 \tan ^{-1}\left(\operatorname{Re}_{f} F^{1.25} / 6.18 \times 10^{4}\right) \\
h_{s p}=0.023 \operatorname{Re}_{f}^{0.8} \operatorname{Pr}_{f}^{1 / 3}\left(k_{f} / D_{h}\right) \\
h_{n b}=0.0122\left(\frac{k_{f}^{0.79} c_{p, f}^{0.45} \rho_{f}^{0.49}}{\sigma^{0.5} \mu_{f}^{0.29} h_{f g}^{0.24} \rho_{v}^{0.24}}\right)\left(T_{w}-T_{s}\right)^{0.24}\left[P_{s a t}\left(T_{w}\right)-P_{f}\right]^{0.75}\end{array}$ & $\begin{array}{l}(75) \\
(76) \\
(77) \\
(78) \\
(79)\end{array}$ & 33.5 \\
\hline Warrier et al. [23] & $\begin{array}{l}h_{s a t}=N u_{3} / N u_{4} \times\left(F h_{s p}\right) \\
F=1+6 B o^{1 / 16}+f(B o) x_{e}^{0.65} \\
f(B o)=-5.3(1-855 B o)\end{array}$ & $\begin{array}{l}(80) \\
(81) \\
(82)\end{array}$ & 88.6 \\
\hline $\begin{array}{l}\text { Steiner and Taborek } \\
\text { [22] }\end{array}$ & $\begin{array}{l}h_{s a t}=N u_{3} / N u_{4} \times\left[\left(F h_{s p}\right)^{3}+\left(F_{n b} h_{n b}\right)^{3}\right]^{1 / 3} \\
F_{c o n v}=\left[\left(1-x_{e}\right)^{1.5}+1.9 x_{e}^{0.6}\left(v_{g} / v_{f}\right)^{0.35}\right]^{1.1} \\
F_{n b}=0.72 F_{P F}\left(q_{c h}^{\prime \prime} / 1.5 \times 10^{5}\right)^{0.8-0.1 e^{1.5 s p_{r}}}\left(D_{h} / 0.01\right)^{-0.4} \\
F_{P F}=2.816 P_{r}^{0.45}+\left[3.4+1.7 /\left(1-P_{r}^{7}\right)\right] P_{r}^{3.7} \\
h_{s p}=0.023 \operatorname{Re}_{f o}^{0.8} \operatorname{Pr}_{f}^{0.4}\left(k_{f} / D_{h}\right) \\
h_{n b}=25,581 \mathrm{~W} / \mathrm{m}^{2} \mathrm{~K}\end{array}$ & $\begin{array}{l}(83) \\
(84) \\
(85) \\
(86) \\
(87) \\
(88)\end{array}$ & 68.0 \\
\hline
\end{tabular}




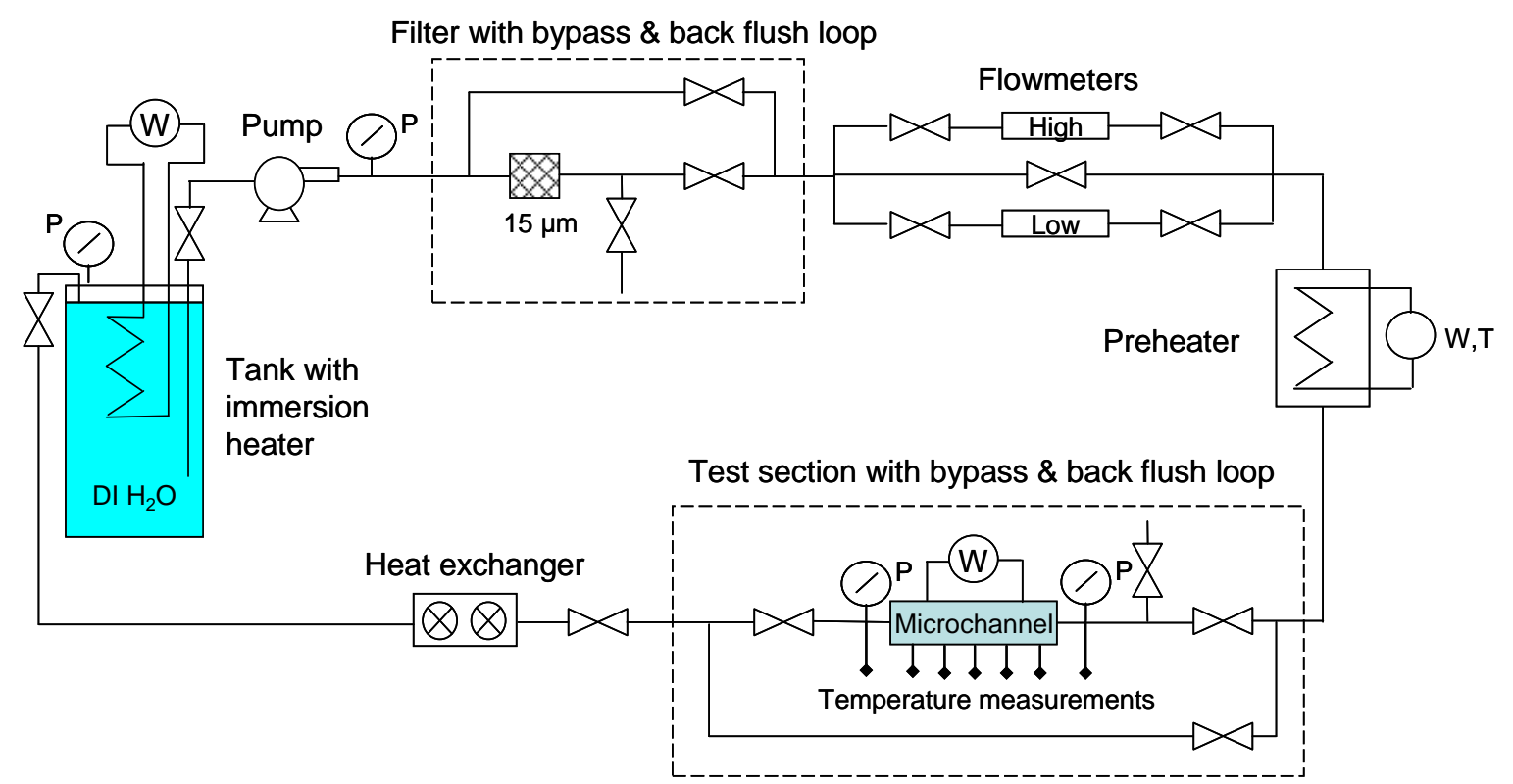

Figure 1. Schematic diagram of experimental test set-up. 


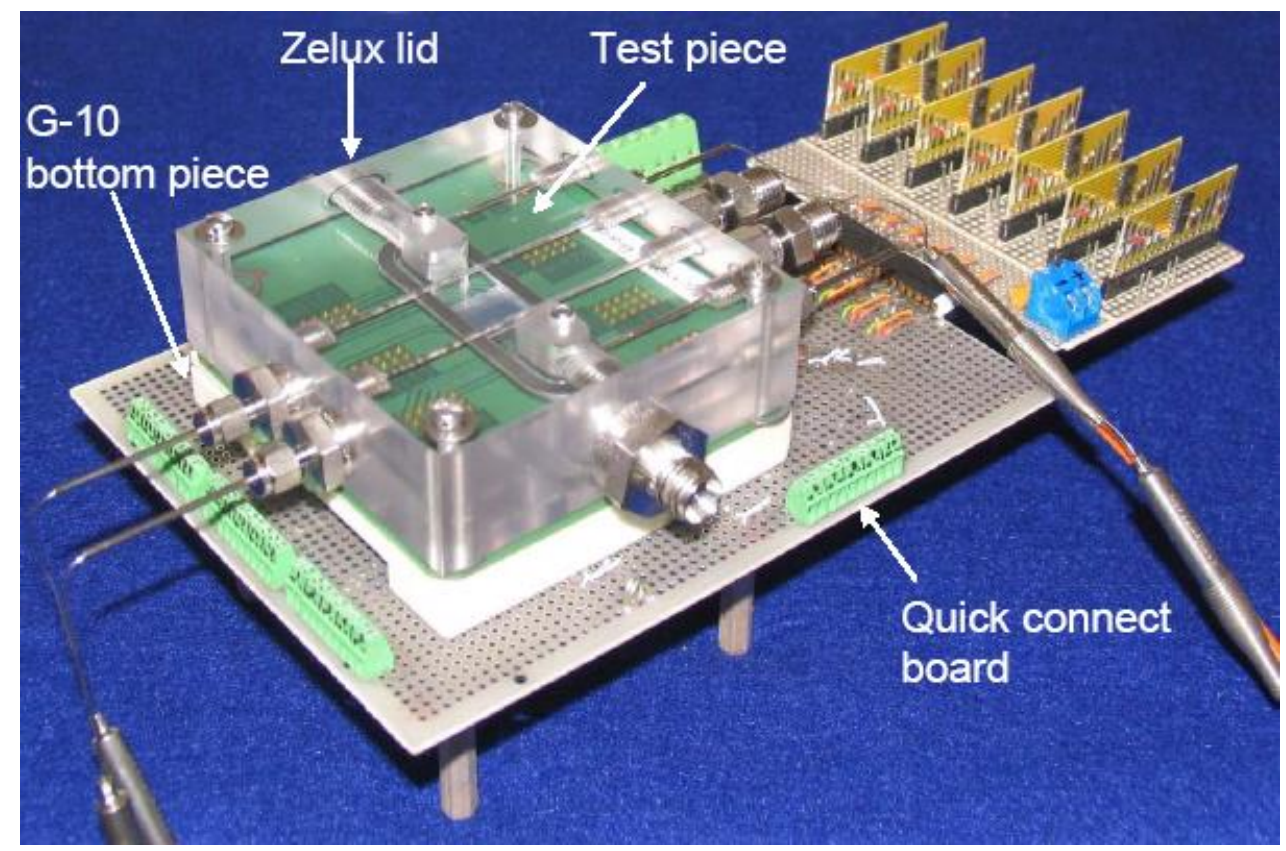

(a)

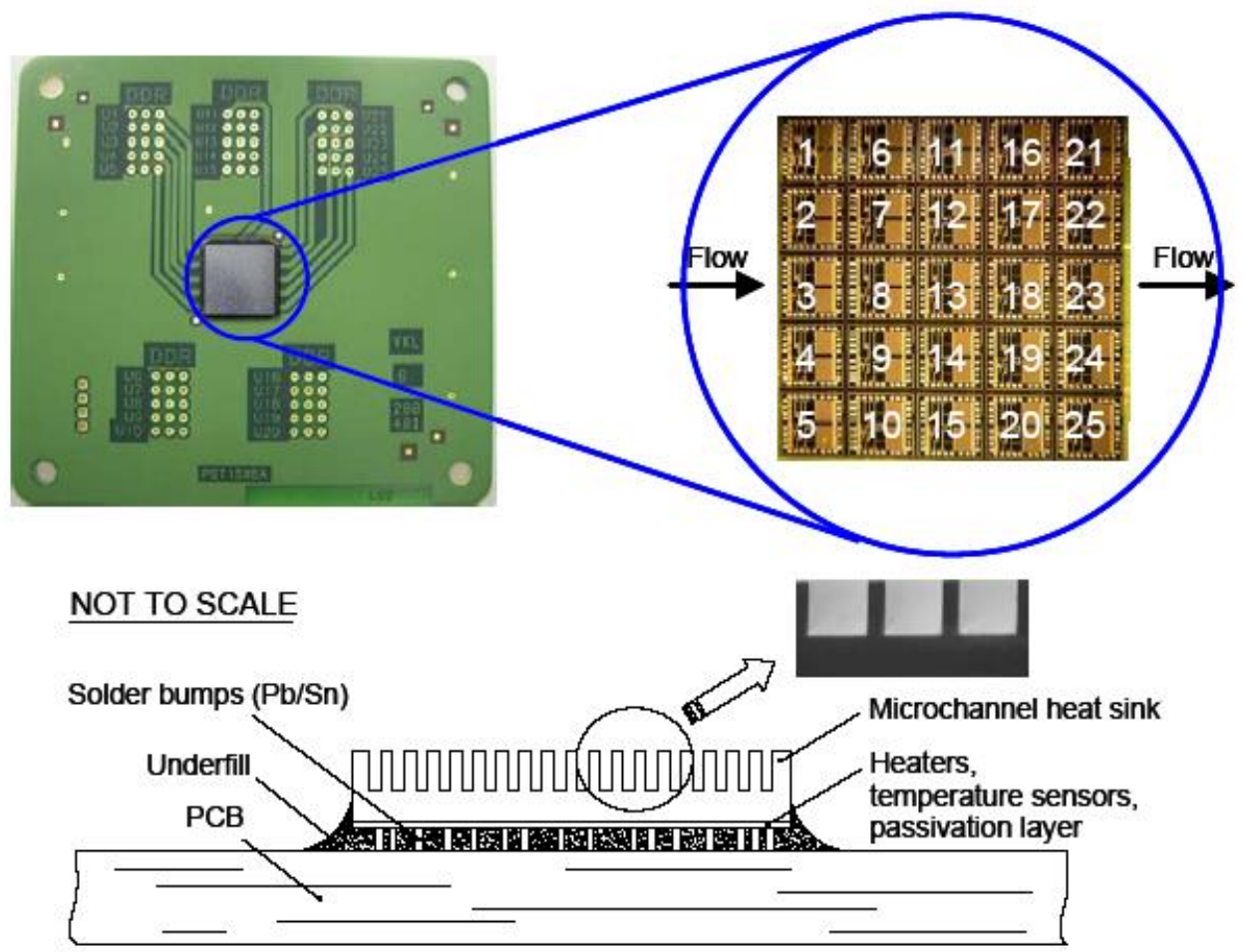

(b)

Figure 2. (a) Microchannel test section, and (b) $5 \times 5$ array of heating elements and integrated diode temperature sensors. 


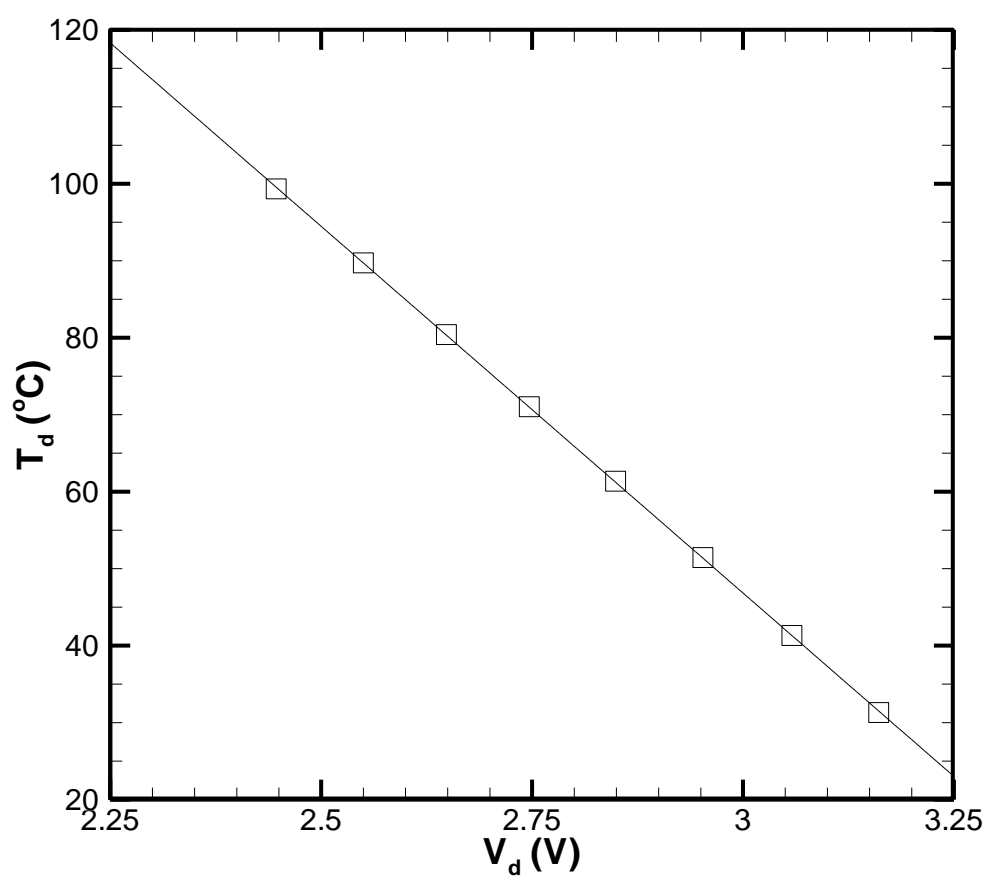

(a)

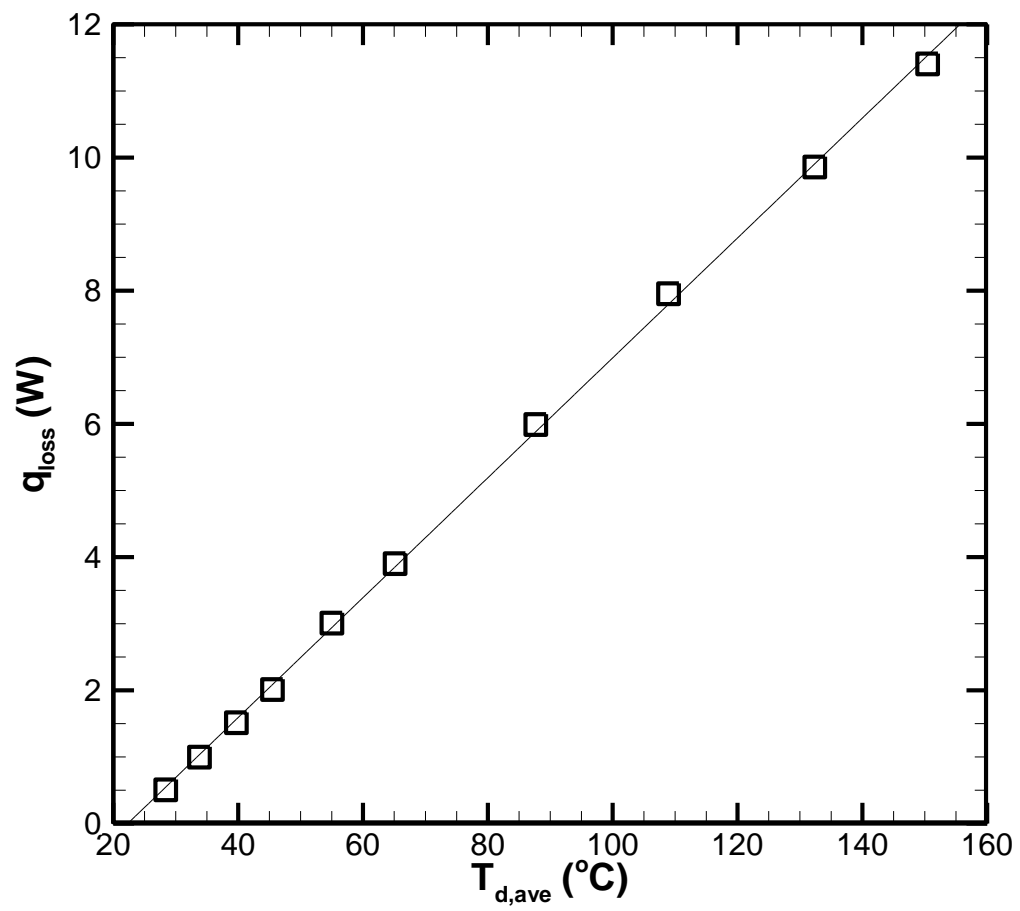

(b)

Figure 3. (a) Typical calibration curve of a silicon diode temperature sensor, and (b) heat loss characterization. 


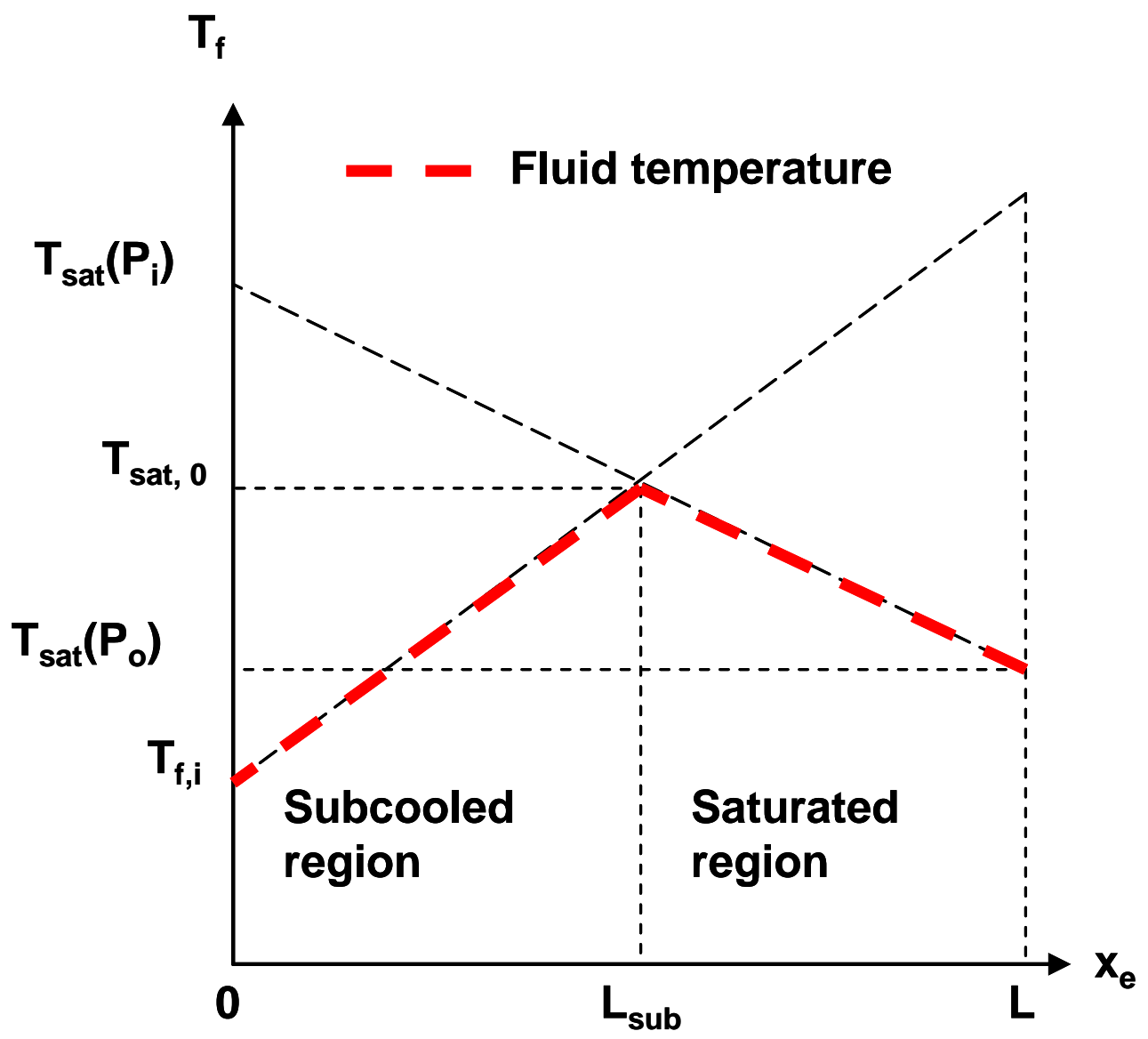

Figure 4. Schematic representation of the fluid temperature along the microchannel. 


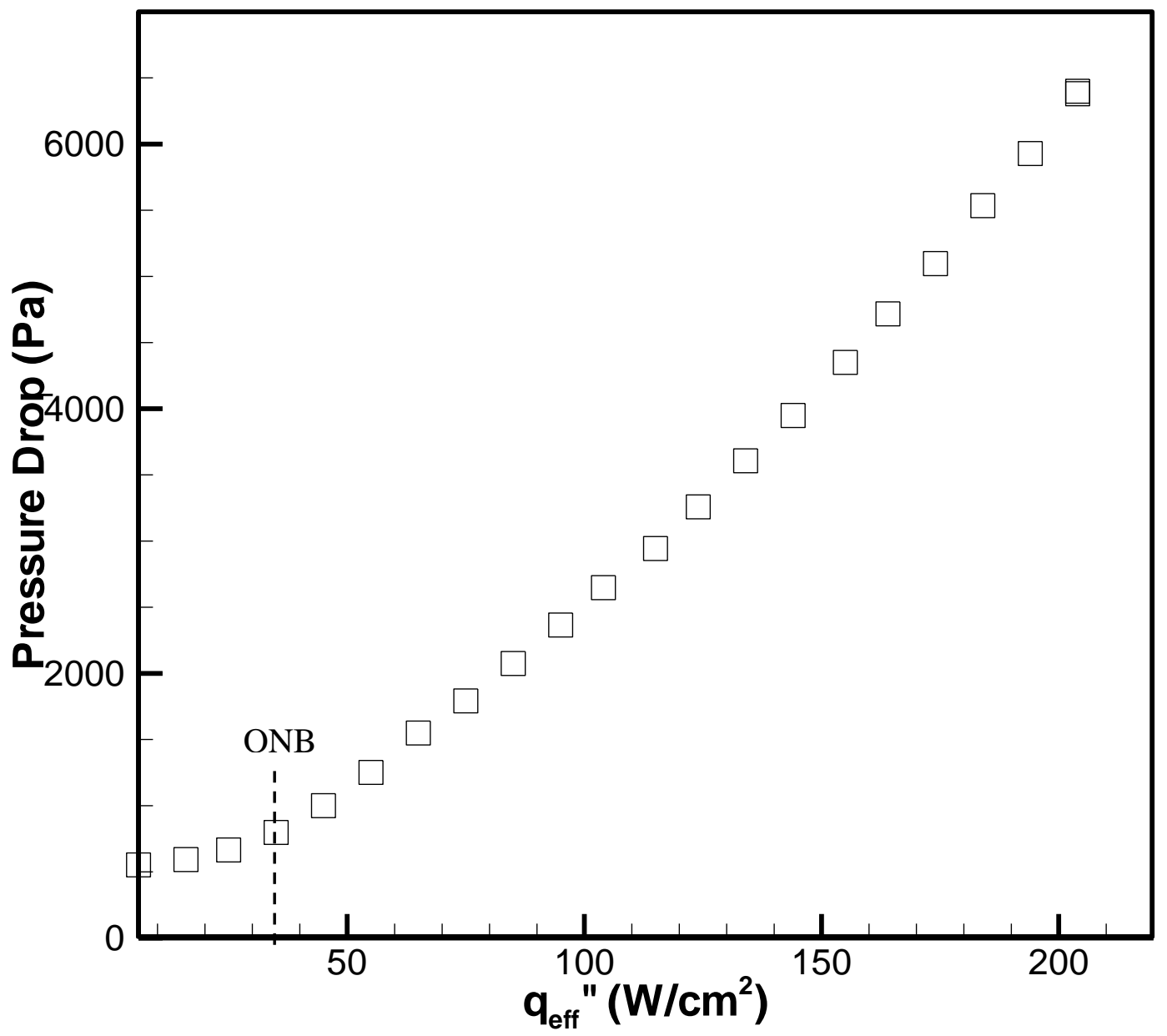

Figure 5. Pressure drop over the length of the microchannels for Case 3-3 $\left(\mathrm{w}=400 \mu \mathrm{m}, \mathrm{H}=398 \mu \mathrm{m}, \mathrm{T}_{\mathrm{f}, \mathrm{i}}\right.$ $=91.3^{\circ} \mathrm{C}$ and $\mathrm{G}=432 \mathrm{~kg} / \mathrm{m}^{2} \mathrm{~s}$ ). 


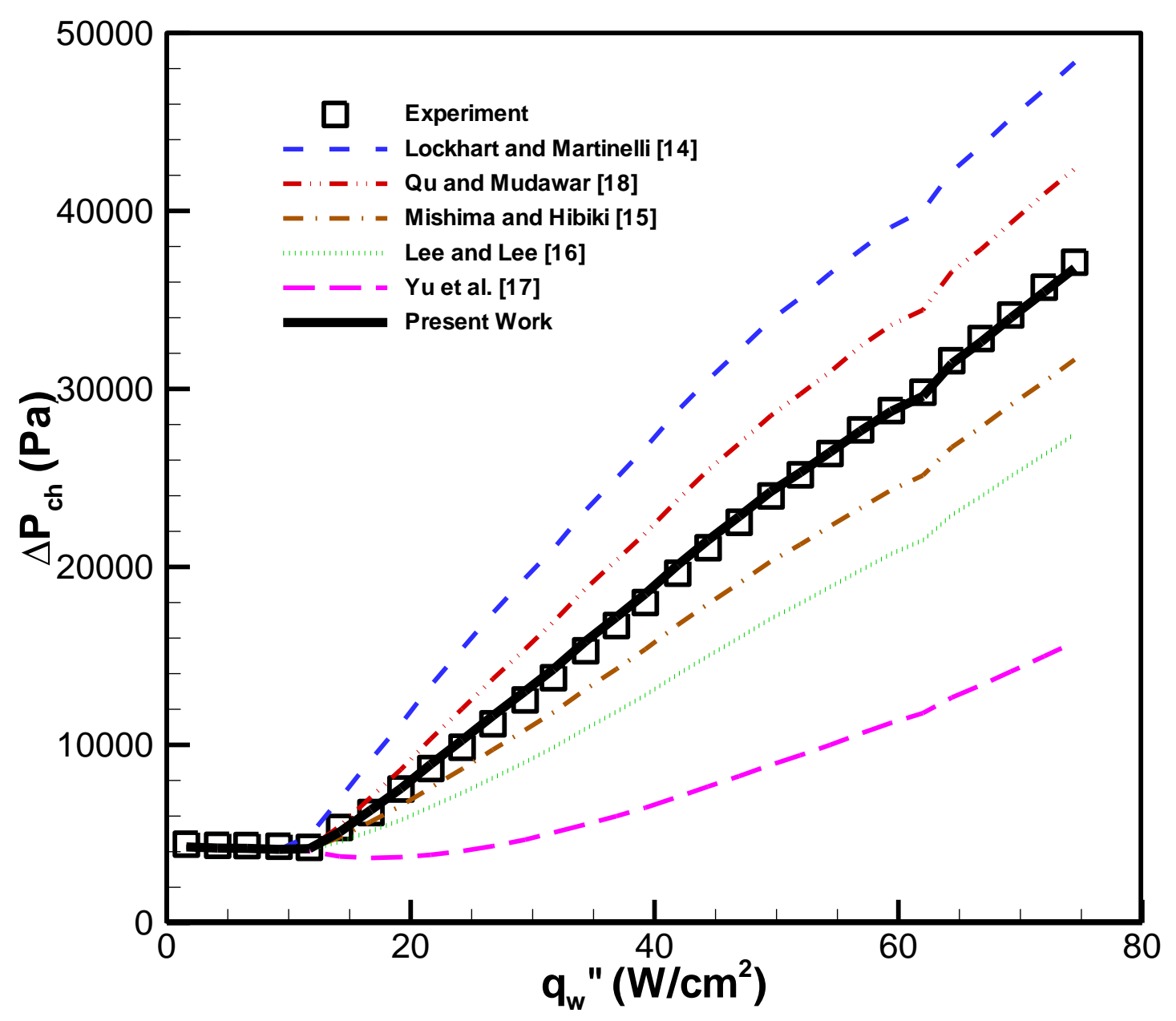

Figure 6. Assessment of correlations in the literature based on comparison with pressure drop over the length of the microchannels for Case $1-5\left(\mathrm{w}=102 \mu \mathrm{m}, \mathrm{H}=367 \mu \mathrm{m}, \mathrm{T}_{\mathrm{f}, \mathrm{i}}=91.1^{\circ} \mathrm{C}\right.$ and $\left.\mathrm{G}=738 \mathrm{~kg} / \mathrm{m}^{2} \mathrm{~s}\right)$. 


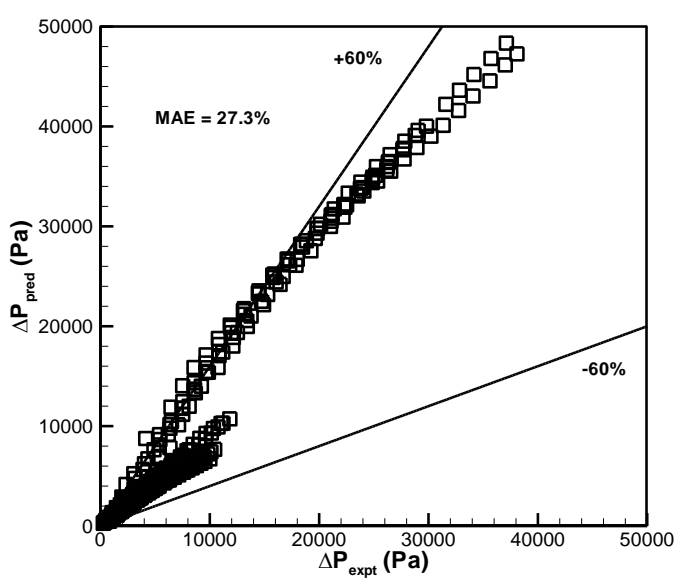

(a)

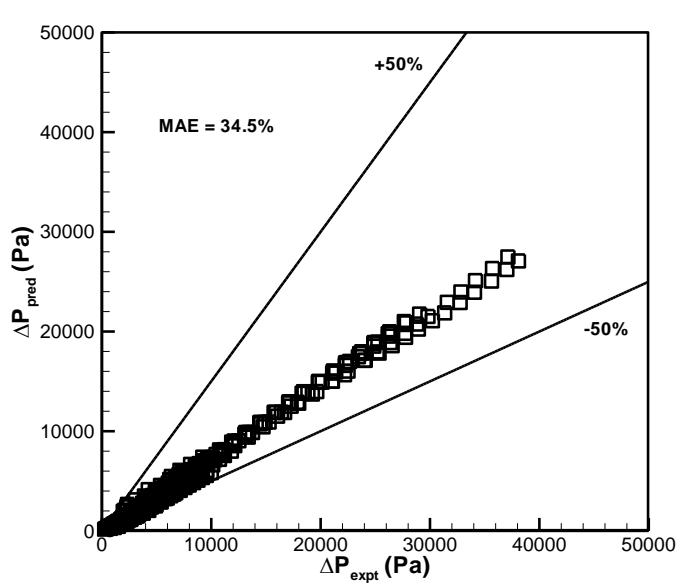

(c)

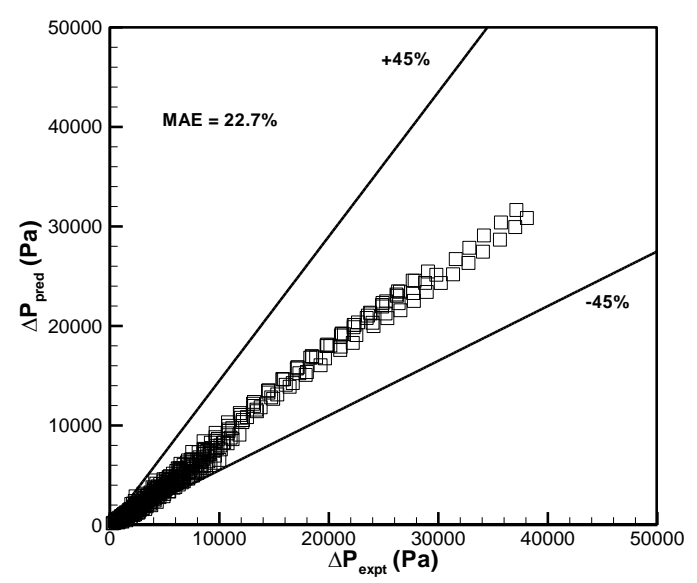

(b)

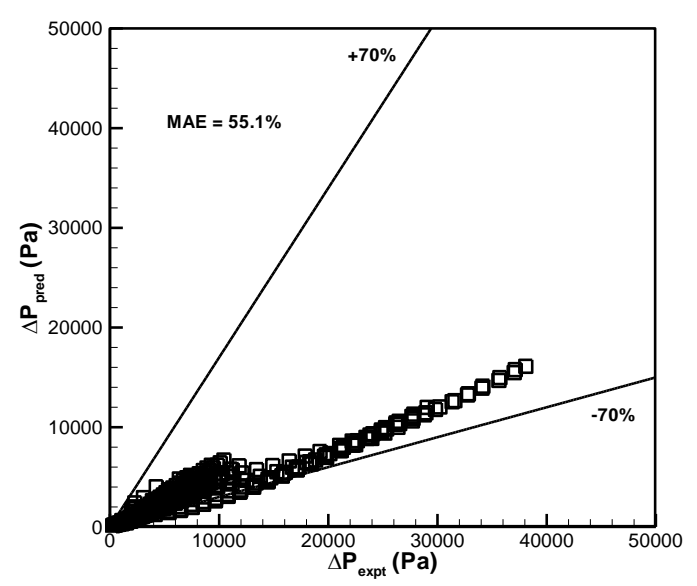

(d)

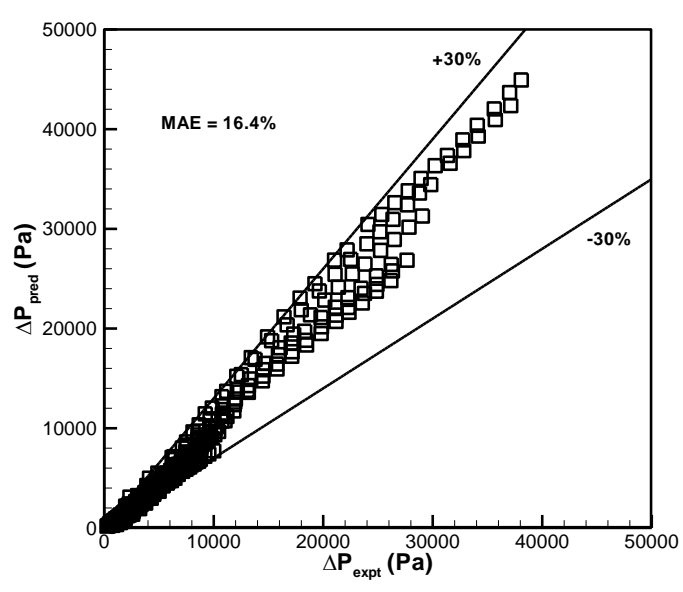

(e)

Figure 7. Comparison of two-phase pressure drop data with predictions by correlations of (a) Lockhart and Martinelli [14], (b) Mishimi and Hibiki [15], (c) Lee and Lee [16], (d) Yu et al. [17], and (e) Qu and Mudawar [18] for all test conditions. 


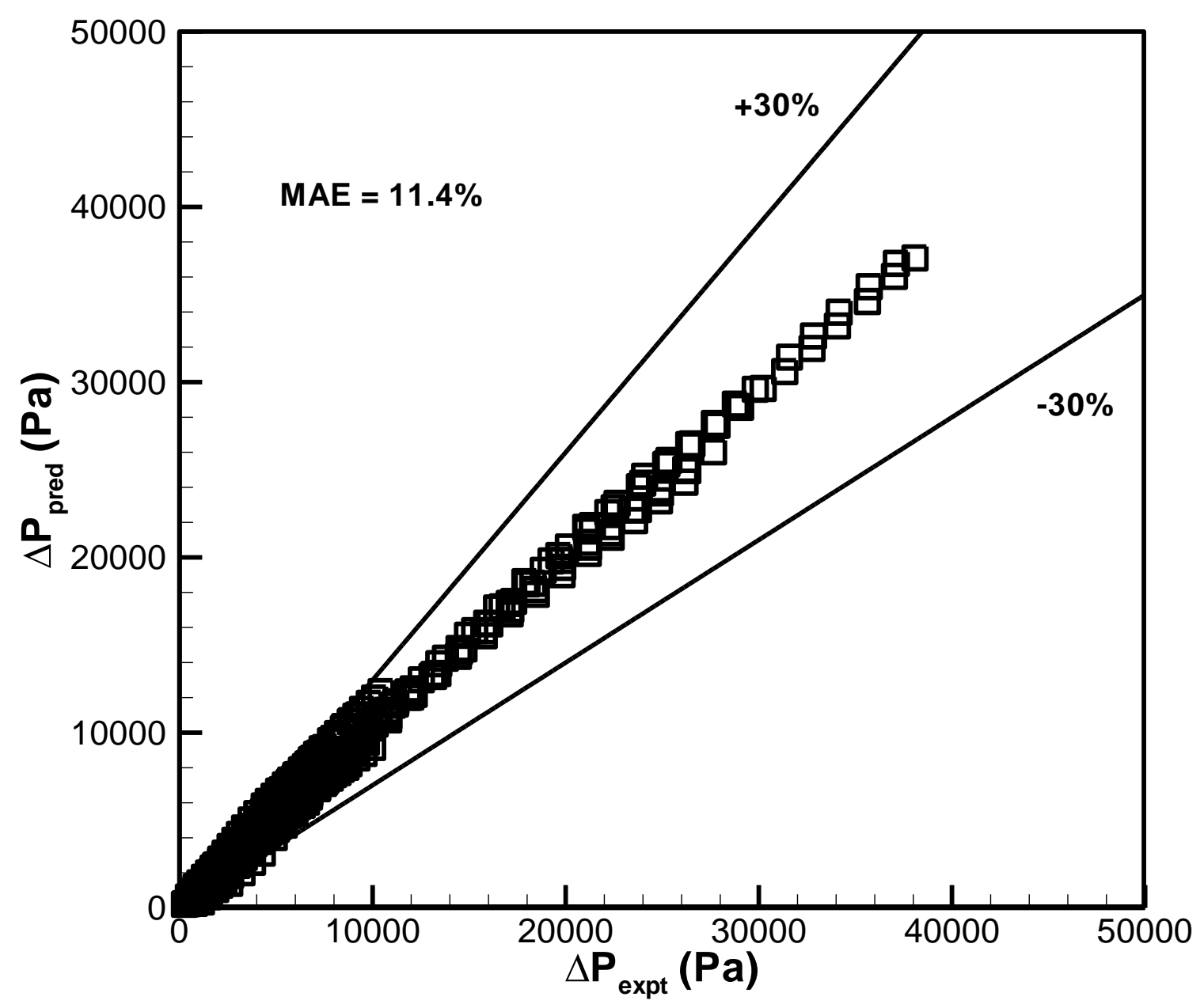

Figure 8. Comparison of two-phase pressure drop experimental data with predictions by proposed prediction for all test conditions. 


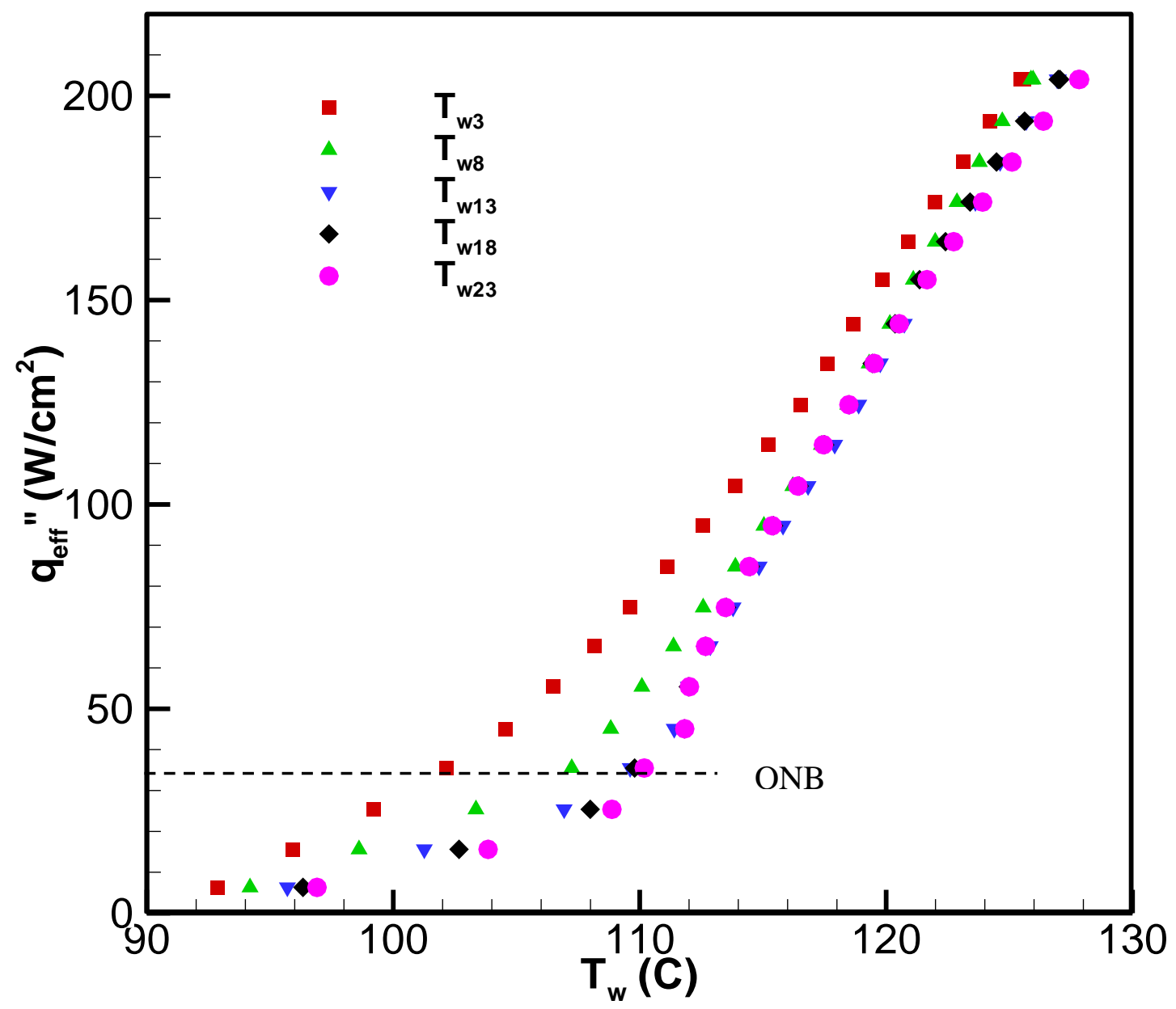

Figure 9. Typical boiling curves measured at five streamwise locations along the center of the chip for Case $3-3\left(\mathrm{w}=400 \mu \mathrm{m}, \mathrm{H}=398 \mu \mathrm{m}, \mathrm{T}_{\mathrm{f}, \mathrm{i}}=91.3^{\circ} \mathrm{C}\right.$ and $\left.\mathrm{G}=432 \mathrm{~kg} / \mathrm{m}^{2} \mathrm{~s}\right)$. 


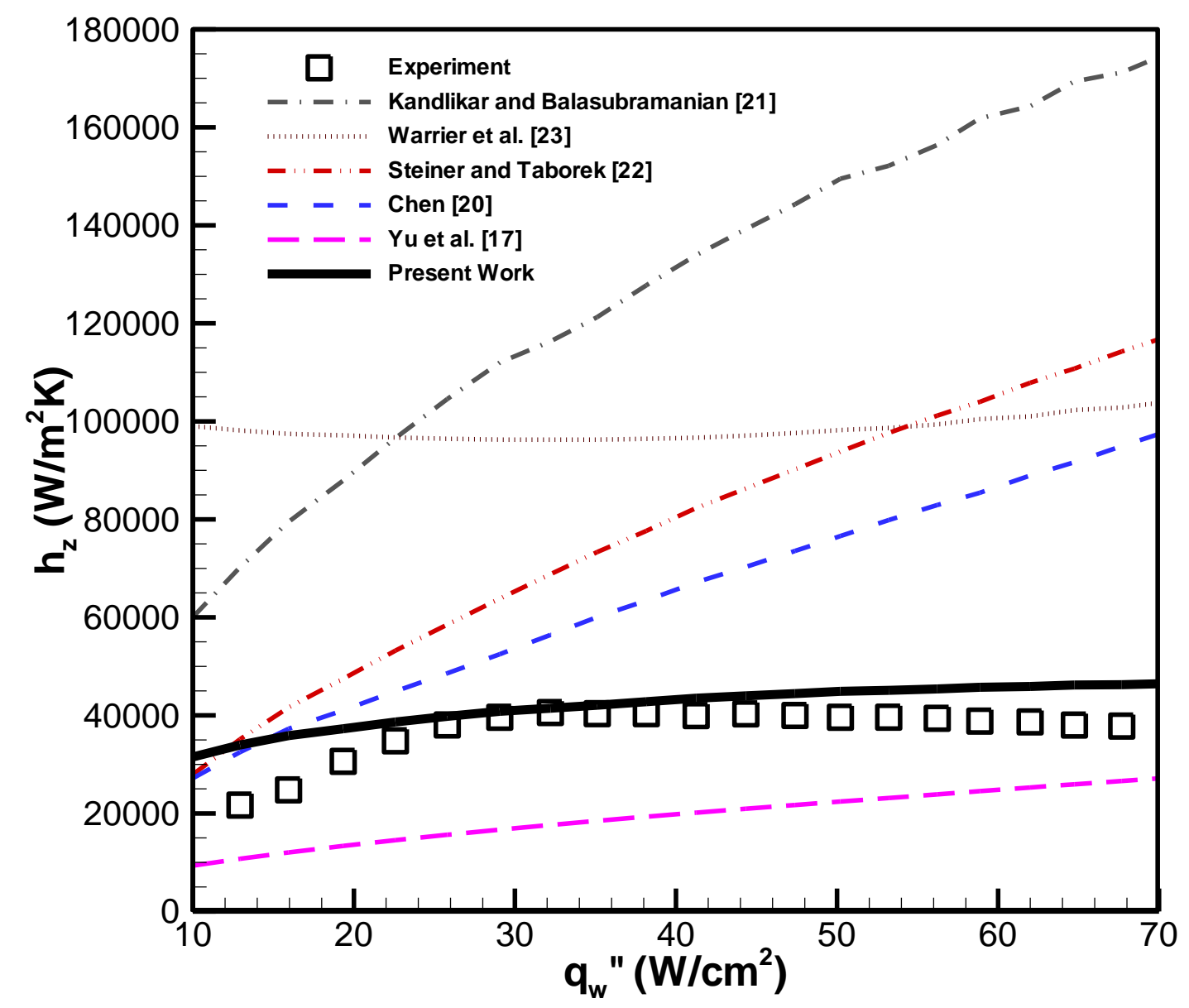

Figure 10. Assessment of correlations in the literature based on comparison with experimental data from the present work at position 23 for Case $1-2\left(\mathrm{w}=102 \mu \mathrm{m}, \mathrm{H}=367 \mu \mathrm{m}, \mathrm{T}_{\mathrm{f}, \mathrm{i}}=93.6^{\circ} \mathrm{C}\right.$ and $\mathrm{G}=368$ $\left.\mathrm{kg} / \mathrm{m}^{2} \mathrm{~s}\right)$. 


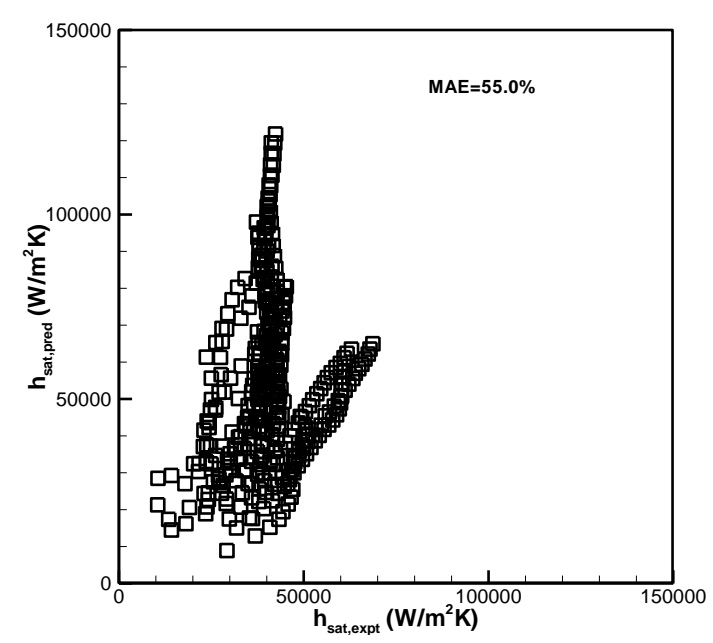

(a)

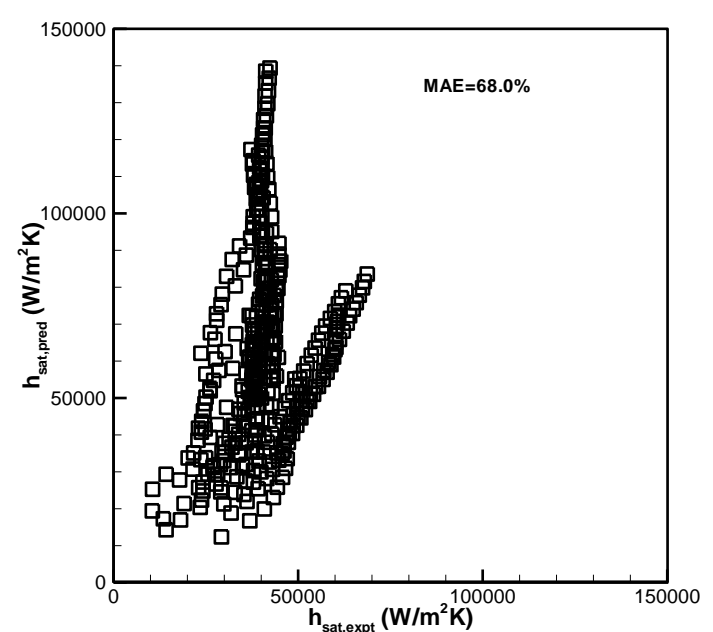

(c)

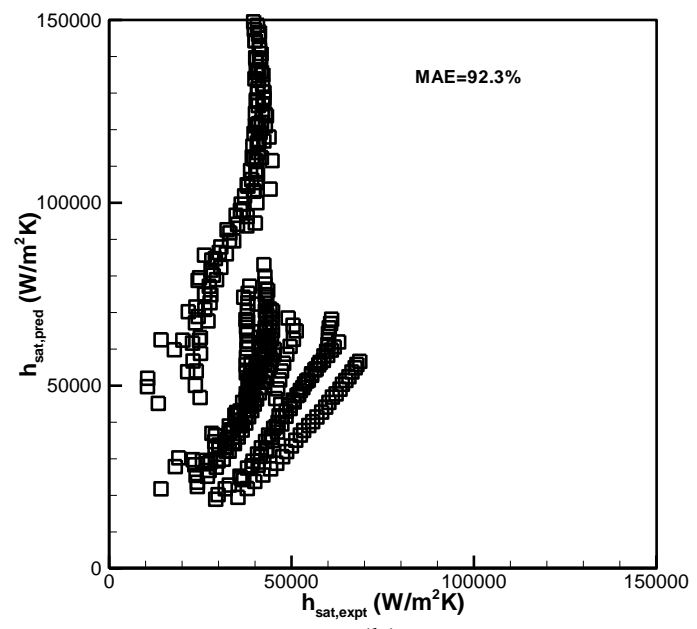

(b)

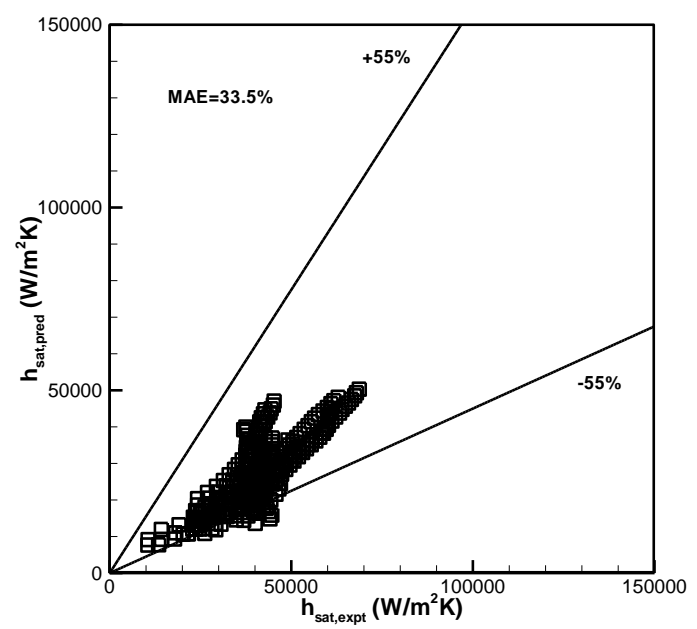

(d)

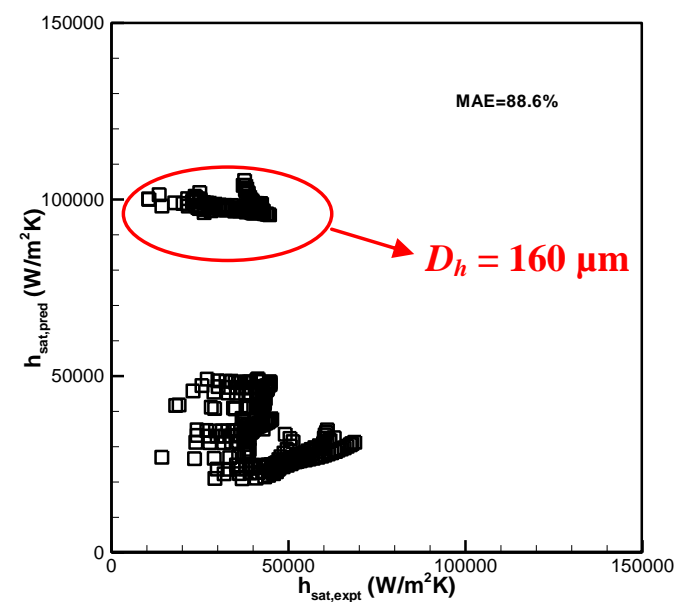

(e)

Figure 11. Comparison of saturated boiling heat transfer data with predictions from the correlations of (a) Chen [20], (b) Kandlikar and Balasubramanian [21], (c) Steiner and Taborek [22], (d) Yu et al. [17], and (e) Warrier et al. [23] for all test conditions. 


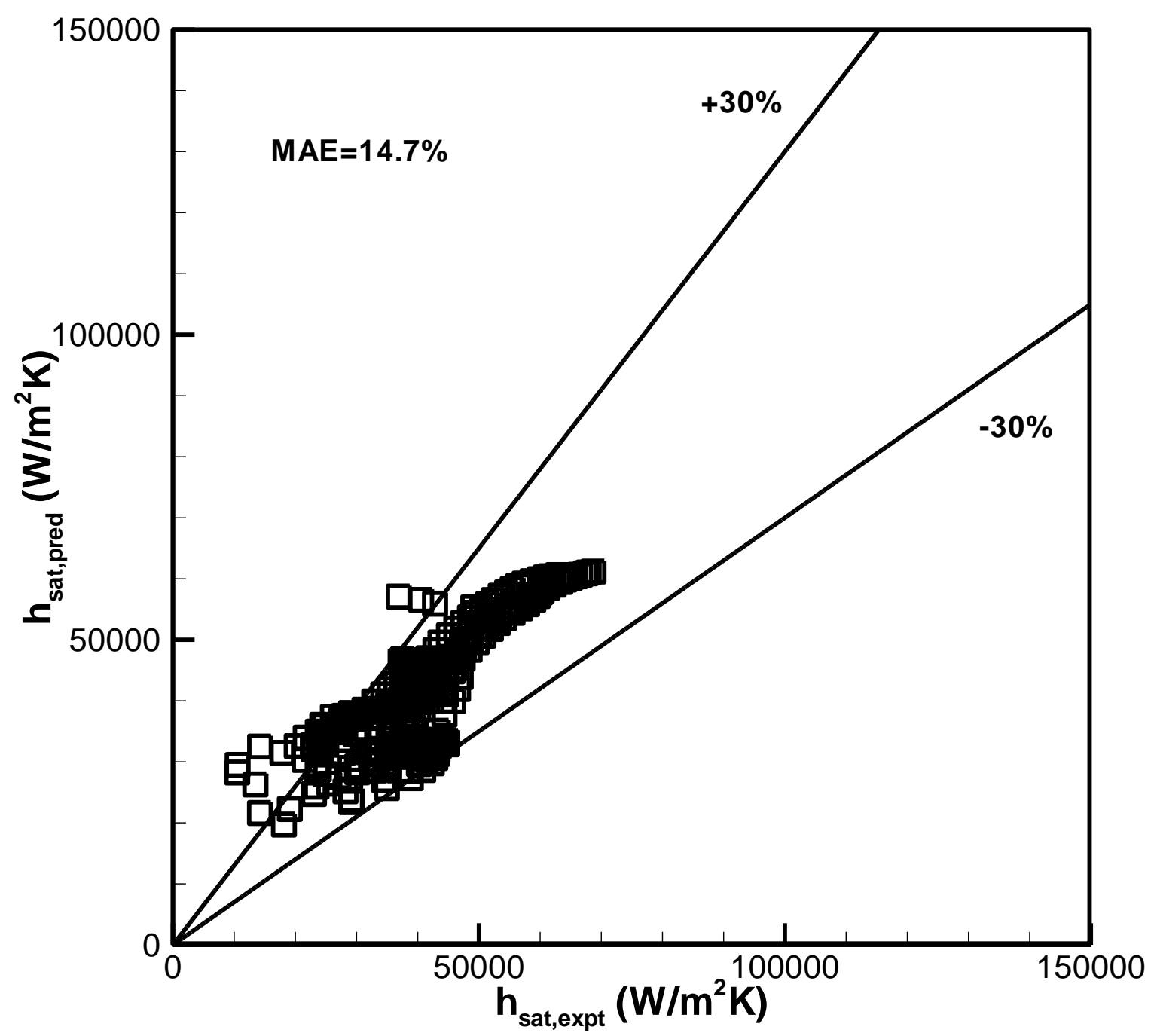

Figure 12. Comparison of saturated boiling heat transfer data with predictions by proposed correlation for all test conditions. 